\title{
Separation correction by speed-adjustment for aircraft on air routes to a congested airport
}

\section{Hirohide Matsunaga}

\author{
Electronic Navigation Research Institute, \\ National Institute of Maritime, Port, and Aviation Technology, \\ 7-42-23 Jindaiji-Higashi-Machi, Chofu, \\ Tokyo, 182-0012, Japan \\ Email: h-matsunaga@mpat.go.jp \\ and \\ Graduate School of Business Science, \\ University of Tsukuba, \\ 3-29-1 Otsuka, Bunkyo-ku, \\ Tokyo, 112-0012, Japan \\ Email: HMBB777@ybb.ne.jp
}

\begin{abstract}
Currently, a minimum separation between aircraft (ACFT) is ensured for safety with time management primarily achieved using two-dimensional (2D) detour coordination. This result in a requirement to balance trade-offs between safety separation, delay times and fuel consumption. This study introduces ACFT speed adjustments in response to the stochastic processes and uncertain factors affecting ACFT separation, including meteorological conditions, instructions on the part of air-traffic control (ATC) and actions on the part of the pilot. In particular, we focus on speed adjustments in one-dimensional (1D) merge routes to improve ACFT separation, delay and fuel consumption. A novel social-welfare (SW) function model is established; subsequently, the relationships amongst the safety value, efficiency and other exchangeable values are confirmed, in addition to determining the optimal point of merging, which was shown to be closer to the alternative merging (zipper) process than the first-come-first-served (FCFS) process.
\end{abstract}

Keywords: air route; speed adjustment; separation correction; alternative merging process; zipper; first-come-first-served process; FCFS; exchangeable value; social welfare; total optimisation.

Reference to this paper should be made as follows: Matsunaga, H. (2021) 'Separation correction by speed-adjustment for aircraft on air routes to a congested airport', Int. J. Mathematical Modelling and Numerical Optimisation, Vol. 11, No. 4, pp.327-354.

Biographical notes: Hirohide Matsunaga is the Senior Director for Research, Electronic Navigation Research Institute (ENRI), National Institute of Maritime, Port and Aviation Technology (MPAT) and originally belongs to the Japan Civil Aviation Bureau (JCAB), Ministry of Land, Infrastructure, Transport and Tourism (MLIT). He is interested in the air traffic management (ATM), aerospace and management engineering field. 


\section{Introduction}

The increased demand for aviation services in recent years has inarguably led to permanent delays in aircraft (ACFT) flights on air routes comprising inter-city air networks. One reason for such delays is order spacing by two-dimensional (2D) route adjustments (called detours) at the merger of congested airports such as Haneda. Iteration of route adjustment is accompanied by uniformly decreasing the values of flight distance, time and fuel consumption; therefore, the aim should be to achieve order spacing by onedimensional (1D) speed adjustment without increasing the distance, (Figure 1). However, ensuring proper separation between ACFT on the same line affects safety and efficiency; shorter separations increase the risk of collisions, whereas longer separations reduce ACFT handling. Moreover, speed-adjustment iterations involve trade-offs between flight safety and fuel consumption. Thus, managing uncertainty and improving accuracy are issues for practical use.

Figure 1 Adjustment of ACFT on the route to the merge

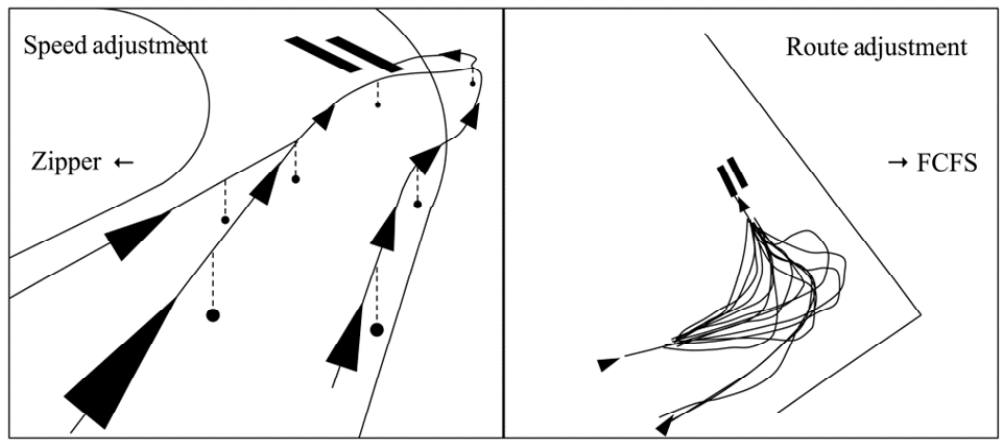

Previously, Sato and Takeuchi (2015) sought precise spacing control for air-route factors but only verified the method using numerical calculations, rather than actual data. Das et al. (2016) reviewed the role of various aviation factors and their impact on reducing fuel consumption, stating that such consumption will be greatly reduced by synergistic effects with the development of air-traffic control (ATC), air routes, runways and taxiways. In ATC, improvement in the skill and system effectiveness of workers can help control delays on air routes; however, the weather cannot be controlled. On air routes, mixed airspaces with crossing and merging routes have a high risk of collision, resulting in traffic jams, inefficient ACFT route selections and excessive fuel consumption. On runways and taxiways, the lack of infrastructure and reduced operational efficiency lead to delays and congestion, increasing fuel consumption and emissions. Menon and Park (2016) performed a review of air-route improvement, focussing on an optimal design, collision avoidance and air-traffic flow management. To match demand and capacity, secure appropriate separations, minimise delays and maximise throughputs, a speed design that optimises energy and time consumption over a short flight distance should be developed for an optimal fuel solution that ensures operational efficiency.

In terms of such a flow management, Kistan et al. (2017) reported that air routes can absorb and maintain delays in air based on a common situational awareness (meteorology and operation) and a balance between demand and capacity. Kim and Hansen (2013) argued that the expense of detouring on a first-come-first-served (FCFS) basis would 
improve with symmetric and sufficient information. Zhang and Mahadevan (2017) determined a detour-optimisation under random variables based on air-traffic uncertainty and stochastic meteorological events.

Furthermore, the time management element common to speed adjustment is detailed in a survey (Hirata and Yai, 2011; Hirata, 2013) on the subjects of delay analysis, delay control, delay and capacity, delay values and related topics. Fukuda et al. (2011) confirmed that their speed adjustment for time management reduced fuel consumption compared with the stagnation offered by route extensions such as detours. This was obtained using a European control authority model (BADA) based on the law of energy conservation. Xu and Prats (2017) stated that unlike during pre-departure ground standby and air standby (holding), deceleration on an air route during a linear standby is locally effective such that fuel consumption is unchanged; this technique is premised on arrivaltime management, and it is necessary for the overall energy balance and improving delays.

However, neither the detour nor the linear standby are the focus of the direct-route and skill-level technique presented by Das et al. (2016). First, the direct air route is energy (fuel consumption) and time (delay) from the viewpoint of ACFT cost improvement and separation (between ACFT) and time (delay); in other words, safety (collision avoidance) and smoothness (traffic flow) are necessary to maintain the order for ATC. Thus, although time delays are common, there is no order-keeping viewpoint. Moreover, neither ATC officers (ATCo) nor ACFT pilots address uncertainties in the model proposed by Das et al. Furthermore, curvilinear detours proposed by Zhang and Mahadevan (2017) increase the delay and flight distance. Xu and Prats (2017) noted an increase in the delays in linear standby and asserted that the divergence between the estimated, scheduled and actual times has not been resolved.

In both the cases, uncertainties in the stochastic processes on the route and the merging of multiple routes are not made into a series of events. For example, in their study on road congestion, Nishi et al. (2009) elucidated the behaviours of two lines with respect to the merging section or junction, unlike previous one-line studies. They analysed the pre-merging arrangement state (which is essential for smooth merging) and discussed the efficiency of a zipper via an alternating arrangement by introducing a local interaction between the two lines. They reported that the risk of collision is reduced and calculated the flow rate of the stochastic model in the system's steady state (i.e., change is in a Markov process). Nevertheless, Nishi et al.'s research is limited to roadside processes without a third party; however, this work focuses on a series of merges and upstream arrangements, which provide a foothold for urban air mobility, e.g. for drones and flying cars.

However, in the International Civil Aviation Organization (ICAO) and its many constituent aviation authorities and operators, the air-traffic management (ATM) system is primarily focused on optimising aircraft operations when faced with uncertain or unknown information, with various autonomous systems supporting decision-makers. ICAO aims to migrate to trajectory-based operations (TBOs), under which each flight is represented using a trajectory shared, managed and used as a common plan for a flight. Moreover, for transient coexistence, speed adjustment, which is considered the key enabler of time management in TBO in ATM, is expected to be applied to UTM, which refers to the traffic management of unmanned aircraft systems (UAS), such as drones, as well as space-traffic management (STM) for super-sonic transportation and space planes, which are called XTM. 
To develop a general accident-analysis model based on the principal influencing factors, Galvao et al. (2018) quantified the factors and assessed those having the greatest impact on the system using Bayesian networks. To propose a tractable computational model to understand the influence of cognitive control and capacity on the speed and accuracy of decisions made in the event-based prospective-memory paradigm, Boag et al. (2019) provided the first detailed quantitative understanding of cognitive gain and focused on applying it to evidence-accumulation models. To develop a theoretical framework containing the methodology for assessing the resilience of ATM affected by the impact of a given disruptive event, Jaksic and Janic (2020) proposed a representation of performance based on indicators such as demand, capacity, traffic complexity, ATCo workload, aircraft/flight delays (and their costs), additional fuel consumption and related greenhouse gas emissions. To achieve TBO and decision-support automation for both the aircraft operator and air-navigation-service providers (ANSPs), Mondoloni and Rosen (2020) reviewed applicable research throughout the trajectory-prediction process, addressed differences in decision-making structures, considered the trajectory-synchronisation research applicable to TBO and required additional accurate trajectory prediction and synchronisation among participants. To characterise the model-prediction uncertainty using a Bayesian approach for increasing in-flight aircraft safety, Zhang and Mahadevan (2020) showed that mixed models exhibited promising performance for predicting flight trajectories and assessing safety during flights. To analyse arrival strategies for minimising aircraft arrival delay while allowing future growth of arrival traffic, Itoh and Mitici (2020) reviewed the management of aircraft arrivals at airports, proposed a data-driven and queue-based modelling approach and presented an analysis of the impact of aircraft arrival in the airspace within a radius of 100 nautical miles around an airport on the delay time. To demonstrate the potential role of UTM, Bijjahalli et al. (2020) reviewed and analysed the major UAS operations, as well as the applicability of various AI/machine learning methods to UAS navigation and autonomous system-integrity monitoring. To facilitate all types of civil UAS operation, Liu et al. (2021) described a typical ANSP-supplied UTM architecture, identified three major ANSP considerations for safely accommodating UASs in civil airspace and outlined future directions and challenges related to UAS operations for ANSP.

Why is FCFS, which consumes large amounts of fuel under 2D detours, selected in ATM? The position and time based on the equations of motion for each ACFT are evaluated with only weather uncertainty, whereas physical events (positioning and timing) remain superposed. Are uncertainties in judgement and selection and a lack of consideration of exchangeable values not attributed to the skill levels of human systems such as ATC and ACFT?

To answer these questions, this study provides a countermeasure focussing on weather, ATC, ACFT uncertainties and exchangeable values on 1D air routes. The aim is to improve the order and value of routes to merge. In particular, we stress that economic parameters such as delay and fuel consumption can be improved when ACFT safety is ensured; thus, the optimal point of merging is shown here. Our answers should help improve current ATM and develop new systems for XTM.

Based on the literature reviewed in this chapter, our current framework is organised in Subsection 2.1 of Section 2; the probabilistic processes before and during merging are modelled in Subsection 2.2, and their validity is analysed in Subsection 2.3. A simulation of the dynamics is presented in Subsection 2.4. The results are summarised in Section 3. 
Finally, in Section 4, the optimal state of merge and its pre-arrangement is discussed based on the current situation of practise and delay.

\section{Research methods}

In this section, a framework of the degrees of freedom and uncertainty between ATC and ACFT is established based on publicly available materials (MLIT, 1969, 2004, 2010; US FAA, 2004; EURO, 2004). This becomes the basis for discussions on weather, ATC, ACFT safety, efficiency, judgement, behavioural uncertainty and trade-offs.

\subsection{Model framework}

This section discusses the framework used to model the merging process of air routes based on existing practices.

First, the procedure for separation correction is organised as follows. Technically, direct routes are preferred for reducing flight distance, time and fuel consumption on an air route. Because each direct route is a part of the route for the merging process, a safety separation between ACFT was enforced to reduce the collision risk. Here, the efficiency can be optimised by correcting the separation fluctuation (over, even and lack) to the minimum safety separation (ATC separation) as quickly as possible. Speed adjustment on the axis of a 1D air route is a form of separation correction.

The speed is adjusted according to the separation between ACFTs on the air route and their time fluctuations (i.e., whether early, on-time or delayed); in other words, time management ensures safety and efficiency.

Delay correction is a measure for reducing the delay [here defined as the difference between the estimated time of arrival (ETA) and actual time of arrival (ATA), with ATA exceeding the scheduled time of arrival (STA)] and the negative delay (including early arrival) of an ACFT passing a certain point. The separation correction ensures end-to-top separations between successive ACFT, secures ATC separation and includes over-ATC separation. Both delay and separation correction affect the delay and ACFT fuel consumption. There are restrictions on combining end-to-top separations, flight statuses and speed adjustments; for example, if there is insufficient front separation, an ACFT should not accelerate, even if it is delayed.

Next, the system uncertainty and stochastic process are established as follows. The separation status and delay in operation are probabilistic, mostly because of the force majeure of the weather and other equipment problems occurring elsewhere. Similarly, speed adjustment is probabilistic and largely depends on the proficiency of ATC and ACFT. Uncertainty is described as a stochastic process (Zhang and Mahadevan, 2017).

Normal ATC is an iterative process where an ACFT request is approved and ACFT makes selections, decisions and actions. Thus, ACFT has a certain degree of independence and freedom.

The merge process describes the probability of coping (axel/brake) with the current status (separation/delay) and the exchangeable value of the result (good/even/bad), where the expected value is given as the sum of the products. In this process, a flight cycle is a series of iterations; for instance, at ACFT $a_{i}, b_{i}$ and ATC $c$ at time $i$ with air routes $(a, b)$ based on the exchangeable value of ACFT separation (over/even/lack), time adjustment (early/on-time/delayed) and fuel consumption (up/even), the sum of the sums of the 
product of the selection probabilities for ACFT $a_{i}, b_{i}$ and ATC $c$ is the social welfare (SW) of the aviation-network system. The continuous combination of high-value processes in the operation cycle optimises (maximise) the SW of the aviation-network system.

The next section describes the flight process of an air route as an iterative system model, considering the existence of an appropriate speed-adjustment point for a proper merging process. The system is generalised with a time index $i$.

\subsubsection{Merge model}

The iteration of merging is described in this section. As a part of the iterative system, hundreds of ACFTs $m_{i}$ and $n_{i}$ on routes $a$ and $b$, respectively, were processed on an FCFS basis and then ordered. This random merge was projected onto a virtual merge route (broken line) before merge route $c$ (Figure 2).

First, several ACFTs were inserted from routes $a$ and $b$.

Figure 2 Random merge (FCFS basis)

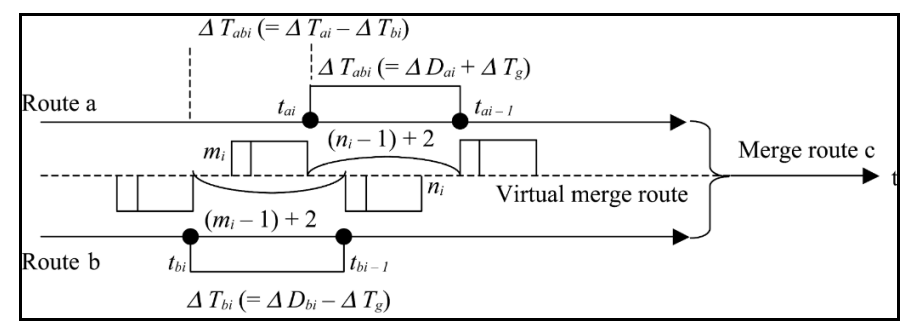

Even if $n_{i}$ ACFT (with $n_{i}+1$ ACFT separations) on route $b$ were inserted between ACFT $a_{i-1}$ and $a_{i}$ on route $a$ (time separation $\Delta T_{a i}$, delay $\Delta D_{a i}$ ) or even if $m_{i}$ ACFT (with $m_{i}+1$ ACFT separations) on route $a$ was inserted between ACFT $b_{i-1}$ and $b_{i}$ on route $b$ (time separation $\Delta T_{b i}$, delay $\left.\Delta D_{b i}\right)$, the time separation between ACFT $\Delta T_{a i} /\left(n_{i}+1\right)$ $=\Delta T_{b i} /\left(m_{i}+1\right)$ was consistent and greater than the ATC separation $\Delta T_{g}$; separation numbers $n_{i}+2$ and $m_{i}+2$ are less than $\Delta T_{g}$.

These variables satisfy the equation

$$
\left(\begin{array}{c}
\Delta T_{a b i}=\Delta T_{a i} /\left(n_{i}+1\right)=\Delta T_{b i} /\left(m_{i}+1\right) \\
\Delta T_{a i} /\left(n_{i}+2\right), \Delta T_{b i} /\left(m_{i}+2\right)<\Delta T_{g} \leq \Delta T_{a i} /\left(n_{i}+1\right)=\Delta T_{b i} /\left(m_{i}+1\right),
\end{array}\right.
$$

where the following relationship between ACFT $a_{i}$ and $b_{i}$ could be projected.

1 projected time separation: $\Delta T_{a b i}\left(=\Delta T_{a i}-\Delta T_{b i}\right)$

2 projected delay: $\Delta D_{a b i}\left(=\Delta T_{a b i}-\Delta T_{g}\right)$

3 ETA of ACFT $i$, i.e., at FIX: $E T A_{i}$

4 STA of ACFT $i$, i.e., at FIX: $S T A_{i}$

5 time separation between subsequent ACFT $i$ and preceding ACFT $i-1$ on each route $a, b: \Delta T_{i}$ 


$$
\begin{aligned}
& \text { ACFT } i \text { delay: } \Delta D_{i}\left(=S T A_{i}-E T A_{i}=S T A_{i}-\left(S T A_{i-1}+\Delta T_{g}\right)\right), \Delta T_{i}\left(=S T A_{i}-S T A_{i-1}\right. \\
& \left.=\Delta D_{i}+\Delta T_{g}\right) .
\end{aligned}
$$

The $\Delta D_{a b i}$ on the virtual merge route then disappeared from $E T A_{i}$ and $S T A_{i}$ and transformed into

$$
\left(\begin{array}{l}
\Delta D_{a b i}-\Delta D_{a b i-1}=-\left(\Delta D_{a i}-\Delta D_{b i}\right)-\left(m_{i}-n_{i}\right)\left(\Delta D_{a b i}+\Delta T_{g}\right) \\
\Delta D_{a b i}-\Delta D_{a b i-1}=-\left(\Delta D_{a i}-\Delta D_{b i}\right)\left(\text { when } m_{i}=n_{i}\right),
\end{array}\right.
$$

In other words, for the zipper with $m_{i}=n i(=1)$, the $\Delta D_{a b i}$ of the preceding ACFT $a_{i}$ and the subsequent ACFT $b_{i}$ on virtual merge route $c$, along with the $\Delta D_{a b i-1}$ of the preceding ACFT pair, were those of the early arrival ACFT $a_{i}$ on route $a$, which could be defined as the difference between $\Delta D_{a i}$ and $\Delta D_{b i}$ for the subsequent ACFT $b_{i}$ on route $b$.

Moreover, if the difference $\left|m_{i}-n_{i}\right|$ for $m_{i} \neq n_{i}$ is counted as zero, both FCFS and zipper could be considered to exhibit the same exchangeable value. Thus, the second expression in equation (2) would be the basis for the correction procedure $i$.

Subsequently, based on the iteration of the delay described in equation (2), $\Delta D_{a b L+1}-d_{2} /\left(1-d_{1}\right)=d_{1}\left(\Delta D_{a b L}-d_{2} /\left(1-d_{1}\right)\right)$ over a sufficiently large time $L$ (= number of units) and the general term $\Delta D_{a b L}=\Delta D_{a b 1} \cdot d_{1}^{L-1}+d_{2} /\left(1-d_{1}\right)\left[d_{1}=1 /\left(m_{i}-n_{i}+1\right) \leq 1\right.$, $\left.d_{2}=\left\{-\left(\Delta D_{a i}-\Delta D_{b i}\right)-\left(m_{i}-n_{i}\right) \Delta T_{g}\right\} /\left(m_{i}-n_{i}+1\right)=0\right]$ of the geometric series with constant terms can be obtained. From the local maximum value of differentiation $d\left(\Delta D_{a b L}\right) / d\left(d_{1}\right)=0\left(\Delta D_{a b 1}(L-1) d_{1}^{L-2}\left(1-d_{1}\right)^{2}+d_{2}=0\right)$, the conditions of the twin pairs $n_{i} \leq m_{i}$ or $m_{i} \leq n_{i}$ are considerably fewer than those of $L\left(n_{i} \leq m_{i}<<\mathrm{L}\right.$ or $\left.\mathrm{mi} \leq n_{i}<<L\right)$.

Therefore, the optimal FCFS basis was close to zipper, where $\left|m_{i}-n_{i}\right|<<L$ included small differences or same values, including 1 .

\subsubsection{Pre-merge model (previous placement)}

This section describes the speed-adjustment iteration on a merge route. In particular, the result of the control and operation of preceding ACFT $a_{i}$ and subsequent ACFT $b_{i}$ for the initial conditions of the end-to-top separation constituted a single event as a new initial separation condition for subsequent ACFT $a_{i+1}$ and further subsequent ACFT $b_{i+1}$, which became an iterative event. Essentially, the total gain of all paths in all event cases was considered when statistically analysing the large number of practical data temporarily stored as non-negative algebra (Figure 3).

In the figure, case refers to a combination of separations at the origin of the initial condition of the event, branch indicates the action of ACFT $a_{i}, b_{i}$ in response to instruction from ATC $c$, and path defines a combination of branches from the starting point to the expected gain (expected value obtained by multiplying the exchangeable value of each event by the probability).

Accordingly, the following occurrence probabilities $\left(0 \leq z_{i}, u_{i}, v_{i}, w_{i}, p_{i}, q_{i}, r_{i} \leq 1\right)$ could be assumed:

a Disturbance probability $z_{i}$ is attributed to weather uncertainty (good: 1); intervention probability $u_{i}$ is attributed to uncertainty in ATC $c$ 's correction.

b Instructions (axel A, brake B, continue C; good: 1). 
c Freedom probabilities $v_{i}$ and $w_{i}$ are attributed to the uncertainties of the actions (yield $\mathrm{Y}$, not yield N) of ACFT $a_{i}$ and $b_{i}$ (yield: 1 ).

d Separation probabilities $p_{i}, q_{i}$ and $r_{i}$ arise from uncertainties such as weather on the air route (Nagaoka et al., 2013) [ATC separation $\Delta T_{g}$ : 1, e.g., $1 \geqq p_{i} \geqq 0,0 \leq 1-p_{i}$ $\leq 1]$. Here, $P_{i}\left(u_{i}, v_{i}, w_{i}, z_{i}\right)$ (preceding ACFT $\left.a_{i}\right), Q_{i}\left(u_{i}, v_{i}, w_{i}, z_{i}\right)$ (medium ACFT $a_{i}$ and $b_{i}$ ) and $R_{i}\left(u_{i}, v_{i}, w_{i}, z_{i}\right)$ (subsequent ACFT $\left.b_{i}\right)$ are on the merge route $c$ of ACFT $a_{i}$ and $b_{i}$ with ATC separation $\Delta T_{g}$. The relevant ratios are $p_{i}=\left(\Delta T_{g}-P_{i}\right) / \Delta T_{g}$, $q_{i}=\left(\Delta T_{g}-Q_{i}\right) / \Delta T_{g}$ and $r_{i}=\left(\Delta T_{g}-R_{i}\right) / \Delta T_{g}$ in the range $\left(0 \leq P_{i}, Q_{i}, R_{i} \leq \Delta T_{g}\right)$.

Furthermore, the sum of the separation probability of each of the eight cases in the initial condition is $\Sigma_{j} f\left(p_{i}, q_{i}, r_{i}\right)_{j}=p_{i} q_{i} r_{i}+p_{i} q_{i}\left(1-r_{i}\right)+p_{i}\left(1-q_{i}\right) r_{i}+\left(1-p_{i}\right) q_{i} r_{i}+p_{i}(1$ $\left.-q_{i}\right)\left(1-r_{i}\right)+\left(1-p_{i}\right) q_{i}\left(1-r_{i}\right)+\left(1-p_{i}\right)\left(1-q_{i}\right) r_{i}+\left(1-p_{i}\right)\left(1-q_{i}\right)\left(1-r_{i}\right)=1$.

Figure 3 Case and path-iterative correction model (Appendix)

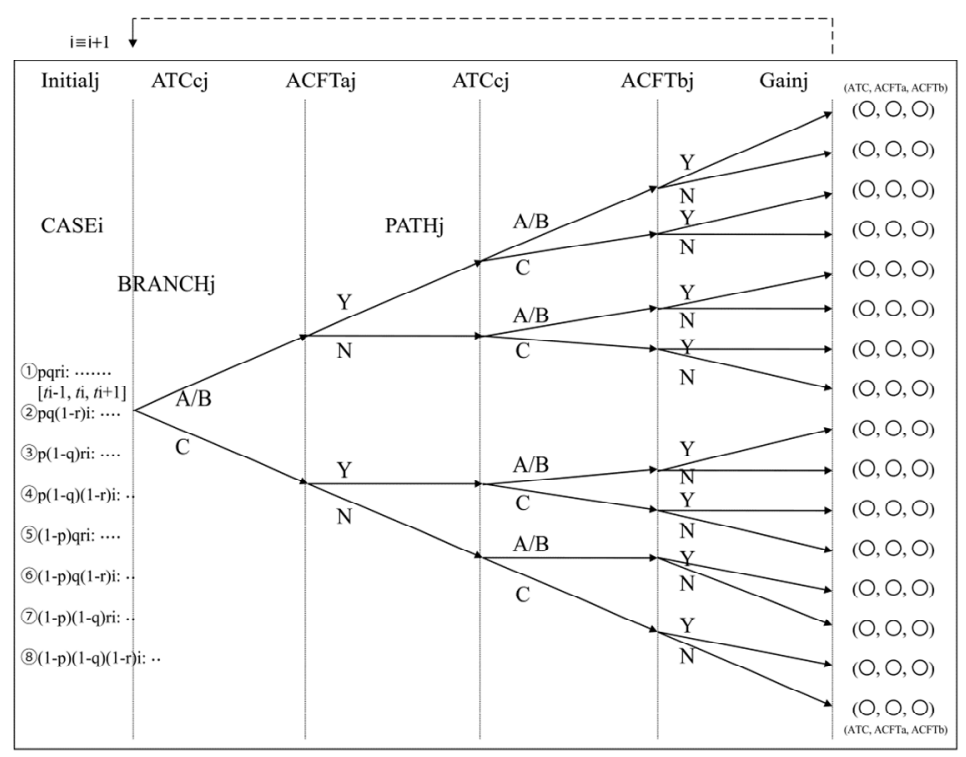

Next, for the exchangeable value of the improvement owing to the instructions from ATC and actions by ACFT (e.g., $\alpha=\Sigma_{i}\left[\alpha_{i} / L\right]_{i=1 \sim L}, 0 \leq \alpha \leq \alpha$ ), the symbol "' indicates "not yield' (non-cooperation); it takes $\pm 1 / 0$ value described as follows.

- $\quad$ time $T$ includes three phases: on-time $\alpha(\alpha)$, delayed $\beta(\beta)$, early $\gamma\left(\gamma^{\prime}\right)$ and $D_{i}(*)$

- $\quad$ separation $S$ includes even $\varphi\left(\varphi^{\prime}\right)$, over $\chi\left(\chi^{\prime}\right)$, lack $\psi\left(\psi^{\prime}\right)$ and $E_{i}(*)$

- $\quad$ fuel $F$ includes up $f\left(f^{\prime}\right)$ and $F_{i}(*)$.

Thus, the equation of the model can be defined as follows:

- The gain (exchangeable value $\times \pm 1 / 0$ value) was obtained from Appendix Tables A2 and $\mathrm{A} 3$. 
The exchangeable value of correction procedure $i$ is then multiplied as follows: "initial condition of air separation $i \Rightarrow$ ATC $c$ instruction $i \Rightarrow$ ACFT $a_{i}$ action $i \Rightarrow$ ATC $c$ instruction $i \Rightarrow$ ACFT bi action $i$."

- The estimated probability is the probability of ATC c's instructions $u_{i}$ and ACFT $a_{i}$, $b_{i}$ 's actions $v_{i}, w_{i}$, which can be used to estimate the effect on the opponent.

- Moreover, the path gain refers to the estimated gain, which is calculated as gain (exchangeable value $\times \pm 1 / 0$ value) $\times$ estimated probability.

- The sum of each case gain (total case gain) is the expected gain, which is the sum of the products of the probability $f\left(p_{i}, q_{i}, r_{i}\right)_{j}$ for each case $j$ and the gain $E_{i}$ (the gain function representing a certain profit or loss for each player).

- The sum of the gains for each path in each case (total path gain, the gains of ATC $c$ and ACFT $a_{i}$ and $b_{i}$ ) is the sum of the gain of the exchangeable value of separation correction $\chi, \psi$; delay correction $\alpha, \beta$; and fuel consumption $f$.

Note that the continuous combination of high-value processing includes the maximisation of the SW of the aviation-network system. ATC for cases (1)-(8) in Appendix Table A4(1) is used for backward induction. Consequently, the maximum path gain and expected gain for each route gain (i.e., c), are obtained (Murota, 2014; OR Society of Japan, 2008).

In each case, the path gains for each player (summed for each player) are the sum of each case in Appendix Table A4(2).

The sums of gains for ACFT $a_{i}$, ACFT $b_{i}$ and ATC $c$, denoted as $E_{a i}, E_{b i}$ and $E_{c}$, respectively, can be defined as follows (Appendix Table A5; here, $|* / * / *|$ represent three choices):

$$
\begin{aligned}
& \left(E a_{i}, E b_{i}, E c\right)=\left(f a_{i}\left(u_{i}, v_{i}, w_{i}\right), f b_{i}\left(u_{i}, v_{i}, w_{i}\right), f_{c}\left(u_{i}, v_{i}, w_{i}\right)\right) \\
& =\sum_{j} f\left(p_{i}, q_{i}, r_{i}\right)_{j} \sum_{i}\left[\left\{|\alpha / \beta / \gamma| D_{i}(*)+|\varphi / \chi / \psi| E_{i}(*)+f F_{i}(*)\right\}\left|u_{i} / v_{i} / w_{i}\right|\right]_{i} .
\end{aligned}
$$

\subsection{Model validity}

In this section, the modelling framework of the merging process on the air route is analytically validated.

\subsubsection{Merge model}

Note that the merge model introduced in Subsection 2.1.1 considers the high-frequency, high-density operational cycle of Japan's major airports. These constitute an air network centred on the Haneda Airport, which has 1,200 daily departing and arriving flights with a two-minute separation. Thus, the Hessian matrix, corresponding to continuous flow with small differences and used to determine the extrema of real-valued functions, is applied for extrema determination to validate the model (Murota, 2014).

Here, the number of ACFT is $m+n$ (with $\mathrm{m}$ on route $a$ and $n$ on route $b$ ) and the numbers of straight branches are $\left(m_{1}, n_{1}\right)$. Furthermore, the exchangeable value based on the straight and loop branches of the direction branch in the state-transition diagram is $U_{1}$ and the numbers of loop branches are $\left(m_{2}, n_{2}\right)$. The exchangeable value is $U_{2}, m=m_{1}$ $+m_{2}, n=n_{1}+n_{2}$. Generally, for each time gain $R$ and discount factor $\delta$ up to time $t$, the 
present value of the total gain is the finite iteration gain $R+\delta R+\delta^{2} R+\delta^{3} R+\ldots+\delta^{t-1} R$ $=R\left(1-\delta^{t}\right) /(1-\delta)$, which has the following respective gain ratios:

$$
\begin{aligned}
& U_{a}=-\left(\delta^{x}+c_{a 1} \delta^{-x}+c_{a 2}\right) U_{1} /(1-\delta), \\
& {\left[c_{a 1}=U_{2} / U_{1} \delta^{m}, c_{a 2}=-\left(U_{1}+U_{2}\right) / U_{1}, x=m_{1}\left(\text { or } m_{2}\right)\right]} \\
& U_{b}=\left(\delta^{v}+c_{b 1} \delta^{-y}+c_{b 2}\right) U_{1} /(1-\delta), \\
& {\left[c_{b 1}=U_{2} / U_{1} \delta^{n}, c_{b 2}=-\left(U_{1}+U_{2}\right) / U_{1}, y=n_{1}\left(\text { or } n_{2}\right)\right] .}
\end{aligned}
$$

Their ratio can be expressed as a gain function:

$$
g(x, y)=U_{b} / U_{a}=\left(\delta^{y}+c_{b 1} \delta^{-y}+c_{b 2}\right)\left(\delta^{x}+c_{a 1} \delta^{-x}+c_{a 2}\right)^{-1}
$$

where $x=y=c, c_{a 1}=c_{b 1}=c_{1}, c_{a 2}=c_{b 2}=c_{2}, \delta \fallingdotseq 1$.

Giving us the Hessian matrix,

$$
\begin{aligned}
& \mathbf{H}(h)=\nabla^{2} g=\left(\begin{array}{cc}
\partial^{2} g / \partial x^{2} & \partial^{2} g / \partial x \partial y \\
\partial^{2} g / \partial y \partial x & \partial^{2} g / \partial y^{2}
\end{array}\right), c_{3}=1+c_{1}+c_{2} \\
& =-c_{3}^{-2}\left(\begin{array}{cc}
-2 c^{2}\left(1-c_{1}\right)^{2} & c^{2}\left(1-c_{1}\right)^{2} \\
\left.+\left\{1+c(c-1)+c_{1}(c+1)^{2}\left(1+c_{1}+c_{2}\right)\right\}\right] & -\{1+c(c-1) \\
c^{2}\left(1-c_{1}\right)^{2} & \left.+c_{1}(c+1)^{2}\right\}\left(1+c_{1}+c_{2}\right)
\end{array}\right)
\end{aligned}
$$

Alternatively, $\partial^{2} g / \partial x \partial y=\partial^{2} g / \partial y \partial x=c^{2}\left(1-c_{1}\right)^{2}$ with $c_{1}=1$ (where $\delta \fallingdotseq 1, c_{2} \fallingdotseq-2, c_{3}=1$ $\left.+c_{1}+c_{2} \neq 0\right)$, which becomes a saddle point for $g$ with both eigenvalues of $\mathbf{H}(g)=-\left(2 c^{2}+c+2\right) / c_{3 \mid} \quad 0\left|\begin{array}{cc}1 & 0 \\ 0 & -1\end{array}\right|$; thus, the true zipper $(x=y=c=1)$ exhibits a minimal eigenvalue and is neither as stable nor as balanced as the total optimisation (Subsection 2.1.1).

\subsubsection{Pre-merge model (previous placement)}

In this section, the model introduced in Subsection 2.1.2 before merging (previous placement) is analytically validated and combined with the virtual route-projection state of the previous stage. The first stage is a stochastic process where the future state is determined from the current state without considering the past state. The transition from each state can be illustrated as a discrete Markov process with a set of possible values of a random variable. A matrix (state-transition matrix) with this transition probability for each factor can be applied to the model described in Okada (2011) and Durrett (2012).

\subsubsection{Path with the maximum path gain and its expected gain}

The path with the maximum path gain and its expected gain, as introduced in Subsection 2.1.3, was organised as follows (Appendix Table A4).

First, in an iterating event, the ATC $c$ does not change and the consecutive ACFT pair $\left(a_{i}, b_{i}\right)$ sequentially change their long-term relationship (Watanabe, 2008). The stochastic 
process state is discrete; thus, the next action is determined only by the present condition and is independent of the previous past action. For instance, path AY-BN denotes the state of instruction and the action of the preceding (ATC $c$, ACFT $a_{i}$ ) and subsequent (ATC $c$, ACFT $b_{i}$ ) groups. Thus, the maximum gain of ATC $c$ (Table 1) for each iteration of the preceding and following iterative events is repeated. Each node $(i, i+1)$, which is a combination of the actions of ACFT $\left(a_{i}, b_{i}\right)$ for the instructions of ATC $c$, is connected by a directional branch $(i, i+1)$ with a path gain.

Figure 4 Iterative state-transition diagram (for convenience, doubled)

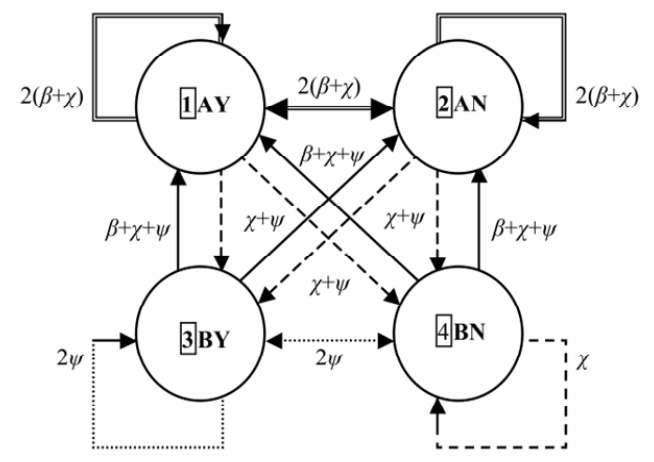

Table 1 State transitions

\begin{tabular}{ccccc}
\hline$i \mid i+1$ & $11 A Y$ & $2 A N$ & $3 B Y$ & $4 B N$ \\
\hline 1 $\mathrm{AY}$ & $(\beta+\chi)\left(v_{i}+w_{i}\right)$ & $(\beta+\chi) v_{i}$ & $\chi v_{i}+\psi w_{i}$ & $\chi v_{i}+\psi^{\prime}\left(1-w_{i}\right)$ \\
& & $+\left(\beta+\chi^{\prime}\right)\left(1-w_{i}\right)$ & & \\
$2 \mathrm{AN}$ & $\left(\beta+\chi^{\prime}\right)\left(1-v_{i}\right)$ & $\left(\beta+\chi^{\prime}\right)\left\{\left(1-v_{i}\right)\right.$ & $\chi^{\prime}\left(1-v_{i}\right)+\psi^{\prime} w_{i}$ & $\chi^{\prime}\left(1-v_{i}\right)+\psi^{\prime}$ \\
& $+(\beta+\chi) w_{i}$ & $\left.+\left(1-w_{i}\right)\right\}$ & & $\left(1-w_{i}\right)$ \\
3 $\mathrm{BY}$ & $\psi v_{i}+(\beta+\chi) w_{i}$ & $\psi v_{i}+\left(\beta+\chi^{\prime}\right)$ & $\psi\left(v_{i}+w_{i}\right)$ & $\psi v_{i}+\psi^{\prime}\left(1-w_{i}\right)$ \\
& & $\left(1-w_{i}\right)$ & & \\
$4 \mathrm{BN}$ & $\psi^{\prime}\left(1-v_{i}\right)$ & $\psi^{\prime}\left(1-v_{i}\right)$ & $\psi^{\prime}\left(1-v_{i}\right)+\psi w_{i}$ & $\psi^{\prime}\left(1-v_{i}\right)+\chi^{\prime}$ \\
& $+(\beta+\chi) w_{i}$ & $+\left(\beta+\chi^{\prime}\right)\left(1-w_{i}\right)$ & & $\left(1-w_{i}\right)$ \\
\hline
\end{tabular}

Note: Previous $i$ and subsequent $i+1$ paths and exchangeable values.

Table 2 Iterative state transitions

\begin{tabular}{lllll}
\hline$i \backslash i+1$ & $1 A Y$ & $2 A N$ & $3 B Y$ & $4 B N$ \\
\hline 1 $\mathrm{AY}$ & $2(\beta+\chi)$ & $2(\beta+\chi)$ & $\chi+\psi$ & $\chi+\psi$ \\
2 $\mathrm{AN}$ & $2(\beta+\chi)$ & $2(\beta+\chi)$ & $\chi+\psi$ & $\chi+\psi$ \\
3 $\mathrm{BY}$ & $\beta+\chi+\psi$ & $\beta+\chi+\psi$ & $2 \psi$ & $2 \psi$ \\
$4 \mathrm{BN}$ & $\beta+\chi+\psi$ & $\beta+\chi+\psi$ & $2 \psi$ & $\chi+\psi$ \\
\hline
\end{tabular}

Note: For convenience, double the display in Table 1. 
Note that with the same estimated probability of $u_{i}, v_{i}, w_{i} \fallingdotseq 0.5$, the expected gain of the direction branch corresponds to the substituting value of the subordinate without the symbol "'. Further, there is no time suffix $i$, similar to dice throwing. Thus, the expected gain converges to a certain value. Here, ACFT $a_{i}$ and $b_{i}$ have similar capabilities corresponding to the average conditions (Table 2 and Figure 4).

Second, in the state transition of iterative events, $\mathbf{P}_{h k}$ is the state-transition matrix (row $h$, column $k$ ), whereas $P_{h k}$ is the transition probability of state $h \Rightarrow k$.

Generally, the transition probability is always 1 when the value added in the row direction of the matrix is called a probability matrix. In the gain matrix $\mathbf{U}_{i h k}$, the matrix factor $h k$ is determined using the gain of the directional branch $h k$ between nodes $h$ and $k$. Furthermore, the state-transition matrix $\mathbf{P}_{h k}$ is determined such that the matrix factor $h k$ is determined by 0 or 1 as a connection between nodes $h k$ (regardless of whether there is a direction branch $h k$ ); the value added in the row direction of the matrix is always standardised to 1 .

The iteration gain is the product of the gain and state-transition matrices. When the iterative state-transition matrix $\mathbf{B}_{h k}$ is normalised to $\mathbf{P}_{h k}$ (which is then iteratively calculated), the state-transition probability and gain matrix of ATC $c$ (when 1 is sufficiently large) are expressed using equation (6).

Third, in steady-state transitions, the transition probabilities can be multiplied. Generally, the transition probability of the $L$ step is the $L^{\text {th }}$ power of the transition probability (OR Society of Japan, 2008); for the following case, brake B is assumed to be greater than axel $\mathrm{A}[\mathrm{A} / \mathrm{B} \cdot \mathrm{Y} / \mathrm{N} \Rightarrow \mathrm{A} \cdot \mathrm{Y} / \mathrm{N}: 0.1, \mathrm{~B} \cdot \mathrm{Y} / \mathrm{N}: 0.4(\mathrm{~A} / \mathrm{B}$ ratio 1:4)] (Fukuda et al., 2011):

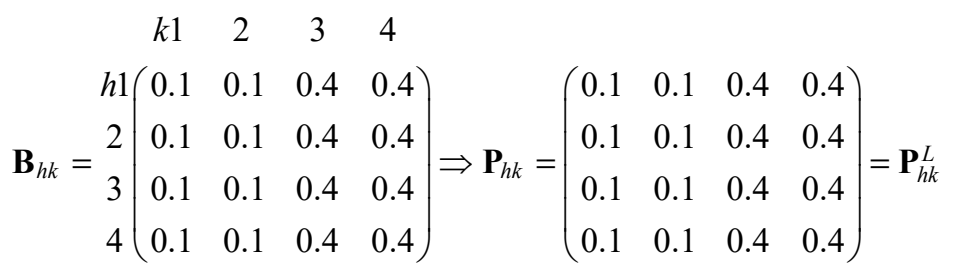

The gain matrix of ATC $c$ is rebate equilibrium by 2 .

$$
\begin{aligned}
& \mathbf{U} c_{i h k} \mathbf{P}_{h k}=1 / 2\left(\begin{array}{cccc}
2(\beta+\chi) & 2(\beta+\chi) & \chi+\psi & \chi+\psi \\
2(\beta+\chi) & 2(\beta+\chi) & \chi+\psi & \chi+\psi \\
\beta+\chi+\psi & \beta+\chi+\psi & 2 \psi & 2 \psi \\
\beta+\chi+\psi & \beta+\chi+\psi & 2 \psi & \chi+\psi
\end{array}\right)\left(\begin{array}{cccc}
0.1 & 0.1 & 0.4 & 0.4 \\
0.1 & 0.1 & 0.4 & 0.4 \\
0.1 & 0.1 & 0.4 & 0.4 \\
0.1 & 0.1 & 0.4 & 0.4
\end{array}\right) \\
& =\left(\begin{array}{l}
1 / 5(\beta+3 \chi+2 \psi) \\
1 / 5(\beta+3 \chi+2 \psi) \\
1 / 10(\beta+\chi+9 \psi) \\
1 / 10(\beta+\chi+9 \psi)
\end{array}\right)
\end{aligned}
$$

Similarly, the gain matrix and iterative gain of ACFT $a_{i}$ and $b_{i}$ are 


$$
\begin{aligned}
& \mathbf{U} a_{i h k}=\left(\begin{array}{cccc}
\beta+\chi+f & \beta+\chi+f & \chi-f & \chi-f \\
\beta+\chi+f & \beta+\chi+f & \chi-f & \chi-f \\
\psi & \psi & \psi & \psi \\
\psi & \psi & \psi & \psi
\end{array}\right) \times 1 / 2 \\
& \mathbf{U} a_{i h k} \mathbf{P}_{h k}=\left(\begin{array}{c}
(\beta+5 \chi-3 f) / 10 \\
(\beta+5 \chi-3 f) / 10 \\
\psi / 2 \\
\psi / 2
\end{array}\right) \\
& \mathbf{U} b_{i h k}=\left(\begin{array}{llll}
\beta+\chi+f & \beta+\chi+f & \psi & \psi \\
\beta+\chi+f & \beta+\chi+f & \psi & \psi \\
\beta+\chi-f & \beta+\chi-f & \psi & \psi \\
\beta+\chi-f & \beta+\chi-f & \psi & \psi
\end{array}\right) \times 1 / 2 \\
& \mathbf{U} b_{i h k} P_{h k}=\left(\begin{array}{c}
(\beta+\chi+4 \psi+f) / 10 \\
(\beta+\chi+4 \psi+f) / 10 \\
(\beta+\chi+4 \psi-f) / 10 \\
(\beta+\chi+4 \psi-f) / 10
\end{array}\right)
\end{aligned}
$$

From equations (10) and (12), ACFT $a_{i}$ and $b_{i}$ are not separately recognised because of alternating iterations $(\beta+5 \chi-3 f=\beta+\chi+4 \psi+f, 5 \psi=\beta+\chi+4 \psi-f, \therefore \beta=0, \chi-\psi=$ $f$ ). Delay $\beta$, which should be absent, has an exchangeable value of 0 , and the difference between the exchangeable values of over $\chi$ and lack $\psi$ is that of the fuel consumption $f$. The delay and separation of the entire system are corrected by speed adjustments following long-term iterations, while the exchangeable value described in Subsection 2.1.2 is ideally reduced to delay $\beta$, over $\chi$, lack $\psi$ and consumption $f$. Furthermore, if $\chi-\psi=0, f=0$, over $\chi$ and lack $\psi$ should be equal.

When the separation is even $\varphi(=\chi=\psi)$ and delay $\beta$ and consumption $f$ are 0 , the flight is ideally safe and economical with no requirement for urgent engine blowing during regular cruises at regular separations.

Considering the conditions $\beta=0$ and $\chi-\psi=f$, the simple sum of all factors in equations (8), (10) and (12) is the indicator

$$
S W F_{1}=(6 \beta+14 \chi+26 \psi) / 5=(6 \beta+40 \chi-26 f) / 5=8 \varphi,
$$

which is the ideal state of the entire system in which delay correction, separation correction and fuel consumption are traded off and balanced by the speed adjustment of the long-term iteration.

Accordingly, the relations indicated in Subsection 2.2.2.1 were the same for the A/B ratio of $1: 1(0.25: 0.25)$, showing that the result is the same regardless of the $\mathrm{A} / \mathrm{B}$ ratio; thus, the following generalisations can be drawn. 


\subsubsection{Total gain sum (gain function) in all cases}

Subsection 2.1.3 showing a sum of the total gain (gain function) in all introduced cases is provided herein. The gain functions $E c, E a_{i}$ and $E b_{i}$ of ATC $c$, ACFT $a_{i}$ and ACFT $b_{i}$, respectively, can be expressed as linear equations (Appendix Tables A4 and A5), as shown in equations (14)-(16), respectively.

Figure 5 Estimated probability and total gain

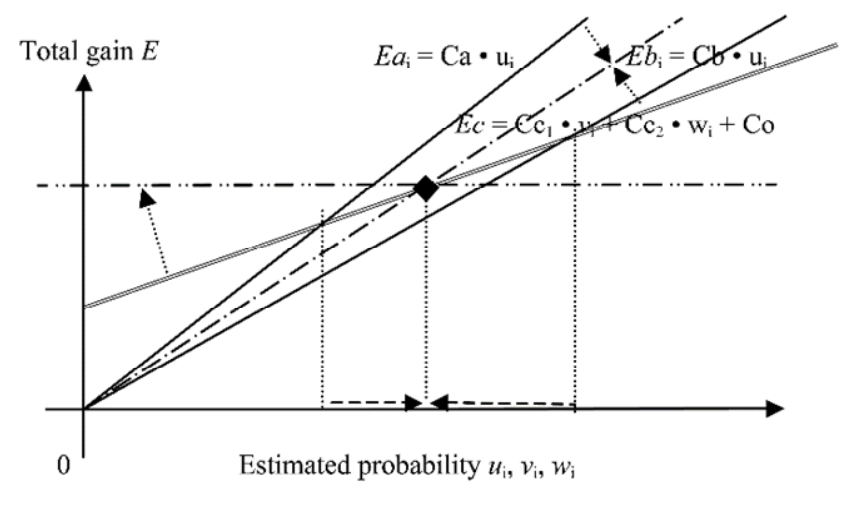

Here, as defined in Subsection 2.1.2, the probabilities $v_{i}, w_{i}, p_{i}, q_{i}$ and $r_{i}$ are averaged and the subordinate values of $\alpha, \beta, \gamma, \varphi, \chi, \psi$ and $f$ (and with the symbol "') are the same. Moreover, the intersection of the three equations with $\beta, f=0$ is optimal overall:

$$
\left(\begin{array}{l}
E c=C c_{1} \cdot v_{i}+C c_{2} \cdot w_{i}+C o \\
E a_{i}=C a \cdot u_{i} \\
E b_{i}=C b \cdot u_{i}
\end{array}\right.
$$

This indicates that in Figure 5, the dashed lines $E a b_{i}=C a b \cdot u_{i}(C a b=C a=C b)$ with the same slopes $C a$ and $C b$ as the straight lines $E a_{i}$ and $E b_{i}$, the slope $C c\left(=C c_{1}+C c_{2}=0\right)$ and the intercept of the double line $E c$ converge to the intersection point $\bullet$ of the two-dotted chain line $E c=C c+C o$ of the constant sum of $C o$ for $E a b_{i}=C a b \cdot u_{i}=E_{c}$ $=C c+C o$ to $u_{i}=C o / C a b$ corresponding to $C o, C a b=3 / 2 \chi+3 \psi-\alpha(\therefore C o / C a b=1)$ to $u_{i}=1$. Ideally, the safety and economic efficiency of the scheduled cruise/adequate control separation before merging (previous stage) with the skilled ATCo and average pilot group are optimal. Furthermore, the optimal SW has the same value as the maximum path with a probability of 1 , and all paths with a total probability of 1 . Accordingly, the ATC Ec and sum of the undivided (Subsection 2.2.2.1) ACFT $a_{i}$ and $b_{i}$ 's $E a b_{i}$ could be expressed as follows:

$$
S W F_{2}=E c+E a b_{i}=C o+C a b=2(3 / 2 \chi+3 \psi-\alpha)=9 \varphi-2 \alpha .
$$

Combining equations (17) and (13) yields $8 \varphi=9 \varphi-2 \alpha$ with $\varphi: \alpha=2: 1$.

The relationship between the exchangeable value of even separation $\varphi$ and on-time $\alpha$, i.e., the ratio between the safety value of the aviation service infrastructure and efficiency value is $\sim 2: 1$. 


\subsection{Dynamic simulation}

Using the analytical results of the ideal state presented in the previous section, restrictions on the use of ATC and actual ACFT data are supplemented with the dynamic simulation using NetLogo Web (1999).

Figure 6 Standby distance, average speed, delay and optimum point (see online version for colours)

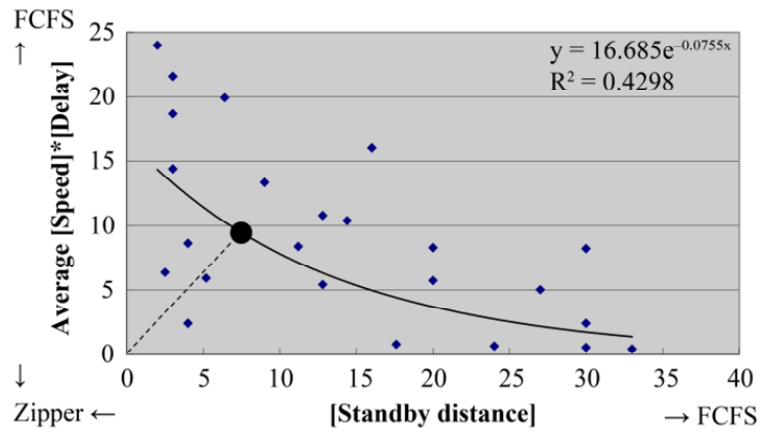

The primary performance of ACFT can be described as follows. At each time step, each ACFT moves forward at its current speed. It accelerates when the current speed is lower than the speed limit and when there are no other ACFT ahead. Otherwise, it decelerates to match the speed of the ACFT ahead. If another ACFT is in a queue in front of the subject ACFT, the algorithm will prompt the subject ACFT to wait in the order of arrival (regardless of the route) in a random order before joining and then join in accordance with the joining operation.

At observation time (ticks) of one-unit time in increments of 1,000 data, three control variables, i.e., the number of ACFTs $(10,20,30,40$ and 50), speed limit (0.1, 0.5 and 1$)$ and waiting times (ticks-per-cycle: 1, 50 and 100), are changed. A long waiting time corresponds to an FCFS in which third-party intervention (i.e., instructions from ATC) is slow, whereas a short waiting time corresponds to zipper. Subsequently, three objective variables, i.e., standby distance, average speed and average delay - exhibit the trade-off relationships shown in Figure 6.

Note that there is an optimal point for adjustment. For the distance dimension in Figure 6, for instance, the origins - which have short lengths of congestion, waiting and detours - are equivalent to alternate merging (zipper) and when there are long retention distances equivalent to FCFS. Here, the optimal point is the point with the best fit exponential curve $y=16.685 \mathrm{e}^{-0.076 x}\left(R^{2}=0.4298\right.$, solid line) and the shortest distance from the origin (dashed line) $\bullet(7.143,9.695)$.

Certainly, the optimum point of merging is formed closer to zipper than to FCFS.

\section{Results}

The above mentioned model builds an SW (gain function) based on the expected value of the probability and occurrence probability of uncertain factors in weather, ATC and ACFT on the air route. The separation is then corrected by speed adjustments. 
In Section 2 - and particularly in the random merging of the current FCFS of multi-route ACFT (Subsection 2.1.1) - the analytical ideal model's reliability is validated by calculating the probability (ATC, ACFT and weather) on the merging route (Subsection 2.1.2) in the modelling process (Subsection 2.2) and determining the judgement extremum using the Hessian matrix (Subsection 2.2.1) and SW on the merging route using the state-transition matrix (Subsection 2.2.2). The model's applicability to speed-adjustment evaluation was confirmed. Moreover, based on the relationship between exchangeable values and the simulation conducted in Subsection 2.3, a more realistic merger algorithm closer to zipper than to FCFS with an optimal point of pre-arrangement (novelty) is obtained.

\subsection{Model framework and validation (merge and pre-merge)}

For merging, an FCFS-based model is obtained as the iteration of delay. In the recurrence formula, the optimal merge point is close to zipper. Based on the Hessian matrix, the zipper is a saddle point and it is not necessarily totally optimal.

Figure 7 State transition of the total optimisation

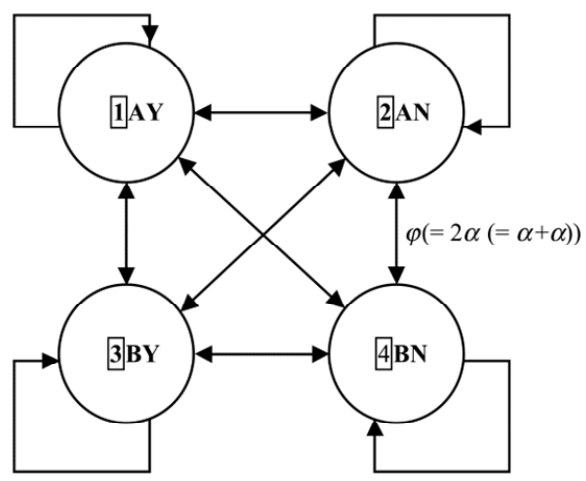

Note: Even separation $\varphi$ and on-time $\alpha$ (cruising).

For pre-merging, the iterated stochastic process of the aircraft group is equated to obtain a continuous combination of high-value processing and the sum of the expected value (gain function). SW is optimised using state transition and gain functions; moreover, it is balanced by the long-term iteration of speed adjustment and can be used for practical applications as a correction index by applying statistical-processing values to a large practical dataset. The probability of algebraic processing is $u=1, v, w, p, q$, $r=1 / 2$ and the exchangeable value is $2 \alpha$ (on-time) $=\varphi$ (even separation) $=\chi$ (over) $=\psi($ lack $), f[$ (irregular) fuel consumption $]=\beta$ (delayed $)=0, \gamma$ (early undecided).

Moreover, in terms of safety and economy, the control separation and scheduled cruising between the skilled ATC and average pilot group in the pre-merge region are optimal, as demonstrated by the relative ratio of the safety value of the aviation infrastructure to the efficiency value of $\sim 2: 1$ (Figure 7). 


\subsection{Dynamic simulation}

Owing to the limited publication and use of actual data for air-traffic operation and control, the dynamics of the merger are simulated using a model. Results indicate a speed-adjustment point for proper merging processing that was closer to the zipper than to the current FCFS.

\section{Discussion}

The Japan Ministry of Land, Infrastructure, Transport and Tourism (MLIT) has subdivided the local airspace into 15 major routes between ten major airports including Haneda and Osaka; these routes are subdivided based on the operational phase (departure/flight/arrival). The ministry performed a gate-to-gate comparison of the 2008 and 2016 data in terms of the time/delay rate and peak value of processing units per hour for ten sectors of the Tokyo Area Control Centre [number of processing units per unit time in peak hours of crowded airspace (MLIT, 2018)].

Figure 8 Total operation time versus delay rate

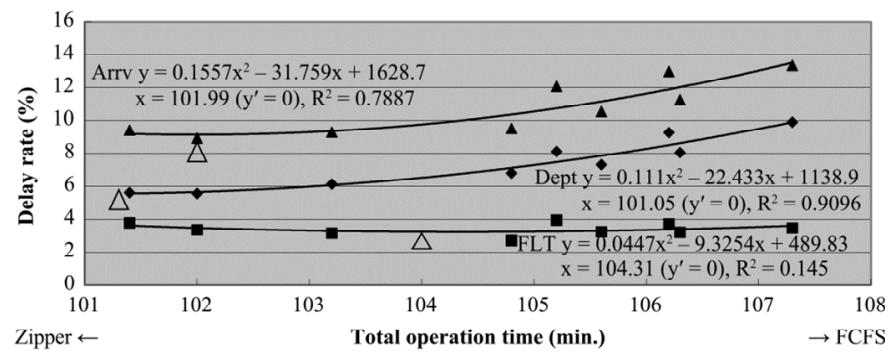

Figure 9 Number of processors per unit time versus delay rate

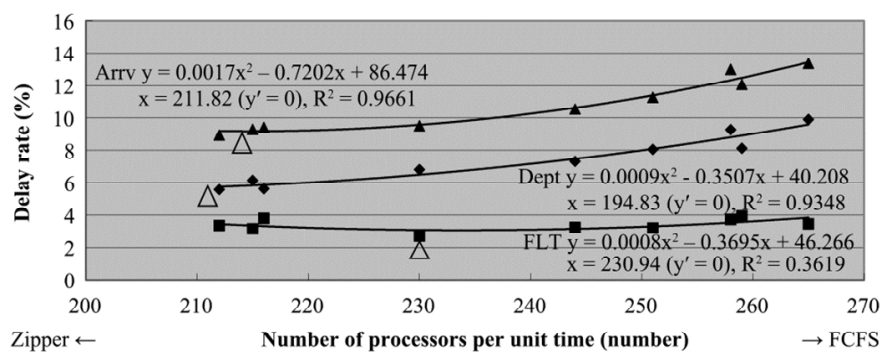

The comparison demonstrates that the total gate-to-gate travel time, departure taxing time, flight time and arrival taxing time have increased by 6, 1, 4 and 1 mins., respectively. Moreover, the flight time first increases and then decreases. Increase in flight time is the most significant finding, which is true on many routes. The comparison determines the arrival-delay (departure-delay) rate, i.e., the ratio of delayed arrival (departure) flights over $15 \mathrm{~min}$ to the total arrival (departure) flights as well as the flight-delay rate [arrival and departure], with differences generally increasing over time. 
Table 3 Total operation time versus delay rate

\begin{tabular}{|c|c|c|c|}
\hline & Fitted functions & Regression fit & Minimum point \\
\hline Arrivals $(\boldsymbol{\Delta})$ & $y=0.1557 x^{2}-31.759 x+1,628.7$ & $R^{2}=0.7887$ & $x=101.99$ \\
\hline Departures $(\bullet)$ & $y=0.1110 x^{2}-22.433 x+1,138.9$ & $R^{2}=0.9096$ & $x=101.05$ \\
\hline In-flight ACFT ( $\mathbf{a})$ & $y=0.0447 x^{2}-9.3254 x+489.83$ & $R^{2}=0.1450$ & $x=104.31$ \\
\hline
\end{tabular}

Table 4 Number of processors per unit time versus delay rate

\begin{tabular}{|c|c|c|c|}
\hline & Fitted functions & Regression fit & Minimum point \\
\hline Arrivals $(\boldsymbol{\Delta})$ & $y=0.0017 x^{2}-0.7202 x+86.474$ & $R^{2}=0.9661$ & $x=211.82$ \\
\hline Departures $(\bullet)$ & $y=0.0009 x^{2}-0.3507 x+40.208$ & $R^{2}=0.9348$ & $x=194.83$ \\
\hline In-flight ACFT (ם) & $y=0.0008 x^{2}-0.3695 x+46.266$ & $R^{2}=0.3619$ & $x=230.94$ \\
\hline
\end{tabular}

Delay rate data were fitted to quadratic functions of the form $y=a x^{2}+b x+c$ to determine the minimum points. Data were divided into arrivals, departures and in-flight ACFT, which is the difference between arrivals and departures. Figure 8 shows the results for the delay rate versus total operation time, and Figure 9 shows the results for the delay rate versus the number of arrivals/departures processed per unit time. In these figures, data for arrivals, departures and in-flight ACFT are represented by triangles $(\mathbf{\Lambda})$, diamonds $(\diamond)$ and squares ( $(\mathbf{)}$, respectively. The fitted functions, regression fit and minimum point of Figures 8 and 9 are given in Tables 3 and 4, respectively.

The delay is positively correlated with the total operational time, which is minimal during the first half of that time ( 100-104 min; Figure 8). Moreover, it shows a positive correlation with the number of processing units per unit time, which is minimal during the first half of the number of processors ( 190-230 numbers of ACFT; Figure 9). There was an increase in the number of unit-time processing units on the air route, total time required and delay rate, followed by congestion and an increased delay because of increased air traffic throughout the flight distance, as well as increased time because of increased detours and air standby. Fuel consumption is expected to increase. In the case of a zipper with on-time direct and express delivery and low processing and the FCFS with orderly and high processing with detour and lagging, the minimal point of flight delay $\triangle$ is suggested to be the optimal point of the system, thereby supporting the speed-adjustment point near the zipper.

As Nishi et al. (2009) reported in the case of random merging in road traffic, when a distance-adjustment section between adjacent lanes is provided in the weaving section (distance-adjustment section before merging) to prevent messy merging, the slow-start (acceleration delay of the stopped car) may incur the possibility that the flow rate at the merge can be improved over the zipper, depending on the setting. Because ACFT cannot be stopped (i.e., there is no slow starting), it is difficult to imagine a situation in which it would be necessary to suddenly adjust the distance to the ACFT on the adjacent air route. In actuality, the ATC adjusts the distance long before the merging point to prevent random merging.

In particular, the distance is merged into a form that is close to a zipper. Thus, an optimal point closer to the zipper is recommended. 
Certain scheduling constraints are handled in the implementation:

1 Equilibrium condition $\varphi=2 \alpha(=\alpha+\alpha)$ between the preceding ACFT $a_{i}$ and the subsequent ACFT $b_{i}$ twin pair indicates that the two ACFTs (on-time $\alpha$ ) have the minimum safety separation (ATC separation $\Delta T_{g}$ ) (even separation $\varphi$ ). In other words, the entire system is at a constant velocity and a constant separation without requiring acceleration or deceleration. This is an ideal state with no scheduling constraints. However, in the control theory describing the transfer function $\left(G(s)=\omega_{n}^{2} /\left(s^{2}+\xi \omega_{n} s+\omega_{n}^{2}\right)\right)$ of the transient response by the Laplace transform, if $\zeta<1$, then the steady-state response is in equilibrium following the transient response (Figure 10).

2 Assuming a sequential transfer function of the series coupling that includes first-derivative terms such as the velocity $\left(G(s)=G(s)_{a} \cdot G(s)_{b}=c_{a 2} /\left(s+c_{a 1}\right)\right.$. $\left.c_{b 2} /\left(s+c_{b 1}\right)=\omega_{n}^{2} /\left(s^{2}+\zeta \omega_{n} s+\omega_{n}^{2}\right)\right)$ between ACFT $a_{i}$ and ACFT $b_{i}$ and the unit-step response of the second-order lag element under the condition $\zeta<1$, the steady-state response is in equilibrium after the transient response.

Therefore, 2 leads to 1 in equilibrium.

Figure 10 Unit-step response of the second-order lag element under condition $\zeta<1$

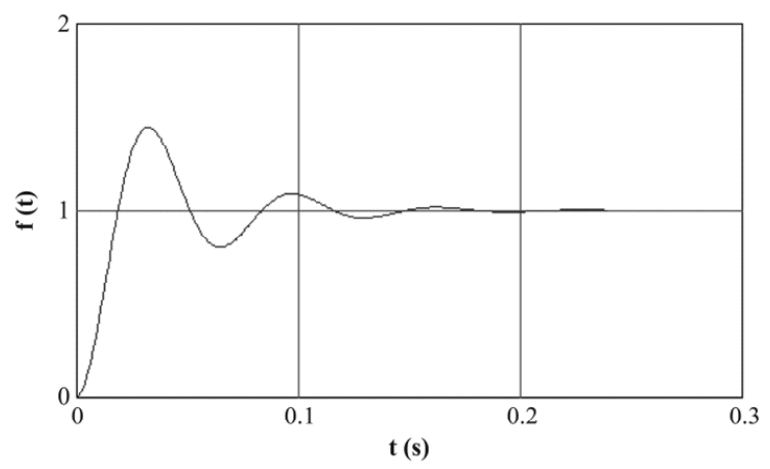

Finally, certain scheduling constraints in the implementation are handled via state monitoring and minimum intervention necessary to prevent divergence. TBO is essentially the sky's high-speed railway network with a command centre. The linear control of the trajectory is time management centred on stochastic speed adjustment, which is common to XTM and is the equilibrium of all interactions, including the stochastic processes of humans, systems and nature. Gradually, the skilled ATCo and average pilot group mentioned in Subsection 2.2.2.2 will be shifted to AI in the forthcoming XTM and even in current ATM. The AI processes a large amount of situational data because of the interaction between humans, systems and nature, and partial autonomy will be enveloped in the balance between total autonomy and automation. The transition from human-based mutual dependence on knowledge and experience to system-based autonomous AI is already underway; however, humans cannot be completely excluded as the final decision-makers because even aviation activities are human in nature. 


\section{Conclusions}

This study evaluates the value of relative freedom rather than the absolute subordination between ATC and ACFT. Factors affecting economic efficiency and safety are considered, and an optimal balance can increase capacity to increase the actual demand.

Furthermore, a series of merging and upstream arrangements and SW-optimisation approaches based on exchangeable values and probabilities of occurrence are applied to the urban air mobility of drones and flying vehicles, free flights of future ACFT, monitor base ATCs with minimum and emergency intervention.

In the future, studies may consider how to obtain the value of algebraic processing and its probability of occurrence, as well as improvement in information sharing based on the realisation that ATC and ACFT information asymmetries restrain flight safety and efficiency.

\section{References}

Bijjahalli, S., Sabatini, R. and Gardi, A. (2020) 'Advances in intelligent and autonomous navigation systems for small UAS', Progress in Aerospace Sciences, Vol. 115, No. 100617, pp.1-32 [online] https://www.sciencedirect.com/science/article/abs/pii/S0376042120300294.

Boag, R., Strickland, L., Loft, S. and Heathcote, A. (2019) 'Strategic attention and decision control support prospective memory in a complex dual-task environment', Cognition, Vol. 191, No. 103974, pp.1-24 [online] https://www.sciencedirect.com/science/article/abs/pii/S001002 7719301350.

Das, D., Sharma, S., Parti, R. and Singh, J. (2016) 'Analyzing the effect of aviation infrastructure over aviation fuel consumption reduction', Journal of Air Transport Management, Vol. 57, pp.89-100 [online] https://www.sciencedirect.com/science/article/abs/pii/.

Durrett, R. (2012) Essentials of Stochastic Processes, Springer/Maruzen Publishing [online] https://services.math.duke.edu/ rtd/EOSP/EOSP2E.pdf (accessed 16 April 2021).

Europe EUROCONTROL and Others (EURO) (2004) SESAR [online] https://ec.europa.eu/ transport/modes/air/sesar_en (accessed 16 April 2021).

Fukuda, Y., Shirakawa, M. and Senoguchi, M. (2011) 'Hikousokudo ni yoru jikankanri no kentou' [Examination of time management by adjusting flight speed]', ENRI 11th Workshop [online] https://www.enri.go.jp/report/hapichi/pdf2011/H23_12.pdf.

Galvao, M., Bandeira, S., Correia, A. and Martins, M.M.R. (2018) 'General model analysis of aeronautical accidents involving human and organizational factors', Journal of Air Transport Management, Vol. 69, pp.137-146 [online] https://www.sciencedirect.com/science/article/abs/ pii/S0969699717304544.

Hirata, T. (2013) 'Mitigation of the delay caused by the special features of runway operation of Haneda airport', JSCE Proceedings D3, Vol. 695, pp.869-879 [online] https://www. jstage.jst.go.jp/article/jscejipm/69/5/69_I_869/_article/-char/ja/.

Hirata, T. and Yai, T. (2011) 'Analysis of ground-holding for Haneda arrivals and airborne delay', 44th Civil Engineering Research Conference, Committee of Infrastructure Planning and Management, Gifu, Japan, pp.1-8 [online] http://trans.civil.ibaraki.ac.jp/hirata/ip2011_gdp. pdf.

Itoh, E. and Mitici, M. (2020) 'Evaluating the impact of new aircraft separation minima on available airspace capacity and arrival time delay', The Aeronautical Journal, Vol. 124, No. 1274, pp.447-471 [online] https://doi:10.1017/aer.2019.160. 
Jaksic, Z. and Janic, M. (2020) 'Modeling resilience of the ATC (air traffic control) sectors', Journal of Air Transport Management, Vol. 89, No. 101891, pp.1-10 [online] https://www.sciencedirect.com/science/article/abs/pii/S0969699720304750.

Kim, A. and Hansen, M. (2013) 'A framework for the assessment of collaborative en route resource allocation strategies', Transportation Research Part C, Vol. 33, pp.324-339 [online] https://www.sciencedirect.com/science/article/pii/S0968090X12000654.

Kistan, T., Gardi, A., Sabatini, R., Ramasamy, S. and Batuwangala, E. (2017) 'An evolutionary outlook of air traffic flow management techniques', Progress in Aerospace Sciences, Vol. 88, pp.15-42 [online] https://www.sciencedirect.com/science/article/abs/pii/S0376042116300458.

Liu, Z., Cai, K. and Zhu, Y. (2021) 'Civil unmanned aircraft system operation in national airspace: a survey from air navigation service provider perspective', Chinese Journal of Aeronautics, Vol. 34, No. 3, pp.200-224 [online] https://www.sciencedirect.com/science/article/pii/ S1000936120303927.

Menon, P. and Park, S. (2016) 'Dynamics and control technologies in air traffic management', Annual Reviews in Control, Vol. 42, pp.271-284 [online] https://www.sciencedirect.com/ science/article/pii/S1367578816300876.

Ministry of Land, Infrastructure, Transport and Tourism (MLIT) (1969) Fifth ATC Processing Rules (Sample) [online] https://www.japa.or.jp/3500 (accessed 16 April 2021).

Ministry of Land, Infrastructure, Transport and Tourism (MLIT) (2004) Koukuki no Anzen Katsu Kouritsuteki na Unkou ni Tsuite (H16.2.25) [Aircraft Safe and Efficient Operation (2004.2.25)] [online] http://www.mlit.go.jp/kisha/kisha04/12/120226/04.pdf (accessed 16 April 2021).

Ministry of Land, Infrastructure, Transport and Tourism (MLIT) (2010) Japan Civil Aviation Bureau (JCAB) Long-Term Vision for Future Air Traffic Systems (CARATS) [online] http://www.mlit.go.jp/common/000128185.pdf (accessed 16 April 2021).

Ministry of Land, Infrastructure, Transport and Tourism (MLIT) (2018) 8th CARATS Promotion Council (2018.3.13) Appendix 2-3 Results of Major Activities in FY2017 (3) Cross-sectional Initiatives, 2, Examination of CARATS Target Indicators) [online] http://www.mlit.go.jp/ common/001230544.pdf (accessed 16 April 2021).

Mondoloni, S. and Rozen, N. (2020) 'Aircraft trajectory prediction and synchronization for air traffic management applications', Progress in Aerospace Sciences, Vol. 119, No. 100640, pp.1-43 [online] https://www.sciencedirect.com/science/article/abs/pii/S037604212030052X.

Murota, K. (2014) Risan Hesse Gyouretsu to Risan Totsu Mansu [Discrete Hessian Matrix and Discrete Convex Function-Positive Definiteness and Discrete Structure], National Graduate Institute for Policy Studies [online] http://www3.grips.ac.jp/ tsuchiya/PSD/slides/murota 140114.pdf (accessed 16 April 2021).

Nagaoka, S., Claus, G. and Fukuda, Y. (2013) 'A probabilistic method for determining the expected departure clearance time based on estimated time of arrival at an en-route fix', IEICE Technical Report, Vol. 112, No. 391, pp.97-102 [online] https://ci.nii.ac.jp/naid/ 110009727510.

NetLogo Web (1999) Traffic Grid [online] http://netlogoweb.org/launch\#http://netlogoweb. org/assets/modelslib/Sample\%20Models/Social\%20Science/Traffic\%20Grid.nlogo (accessed 16 April 2021).

Nishi, R., Miki, H., Tomoeda, A. and Nishinari K. (2009) 'Inverse efficiency between alternative and random merging caused by a slow-to-start effect', Journal of Japan Society of Applied Mathematical Sciences, Vol. 19, No. 4, pp.519-536 [online] https://www.jstage.jst.go.jp/ article/jsiamt/19/4/19_KJ00005931690/_article/-char/ja/(accessed 16 April 2021). 
Okada, A. (2011) Game Riron [Game Theory], Yuhikaku [online] https://www.amazon.co.jp/ \%Е3\%82\%B2\%E3\%83\%BC\%Е3\%83\%A0\%Е7\%90\%86\%Е8\%AB\%96-\%Е6\%96\%B0\%Е7 $\% 89 \% 88-\%$ E5\%B2\%A1\%E7\%94\%B0-\%E7\%AB\%A0/dp/4641163820 (accessed 16 April 2021).

OR Society of Japan (2008) OR Dictionary [online] http://www.orsj.or.jp/ wiki/wiki/ index.php/\%E5\%BE\%AE\%E5\%88\%86\%E4\%B8\%8D\%E5\%8F\%AF\%E8\%83\%BD\%E6\%9C $\% 80 \% \mathrm{E} 9 \% 81 \% \mathrm{~A} 9 \% \mathrm{E} 5 \% 8 \mathrm{C} \% 96$ (accessed 16 April 2021).

Sato, M. and Takeuchi, N. (2015) 'Feasibility study on smooth merging through air traffic controller's speed instruction', Journal of the Japan Aerospace Society, Vol. 636, pp.248-256 [online] https://www.jstage.jst.go.jp/article/jjsass/63/6/63_63_248/_article/-char/ja/.

US Federal Aviation Administration (FAA) (2004) NextGen [online] https:/www.faa.gov/nextgen/ (accessed 16 April 2021).

Watanabe, T. (2008) Seminar Game Riron Nyumon [Introduction to Seminar Game Theory], Nikkei Publisher [online] https://www.nikkeibook.com/item-detail/13346 (accessed 16 April 2021).

$\mathrm{Xu}, \mathrm{Y}$. and Prats, X. (2017) 'Effects of linear holding for reducing additional flight delays without extra fuel consumption', Transportation Research Part D, Vol. 53, pp.388-397 [online] https://www.sciencedirect.com/science/article/pii/S1361920916308501.

Zhang, X. and Mahadevan, S. (2017) 'Aircraft re-routing optimization and performance assessment under uncertainty', Decision Support Systems, Vol. 96, pp.67-82 [online] https:// www.sciencedirect.com/science/article/pii/S0167923617300210.

Zhang, X. and Mahadevan, S. (2020) 'Bayesian neural networks for flight trajectory prediction and safety assessment', Decision Support Systems, Vol. 131, No. 113246, pp.1-17 [online] https://www.sciencedirect.com/science/article/abs/pii/S0167923620300014. 


\section{Appendix}

Table A1 Tree example [case (1) $p_{i} q_{i} r_{i}$ ]

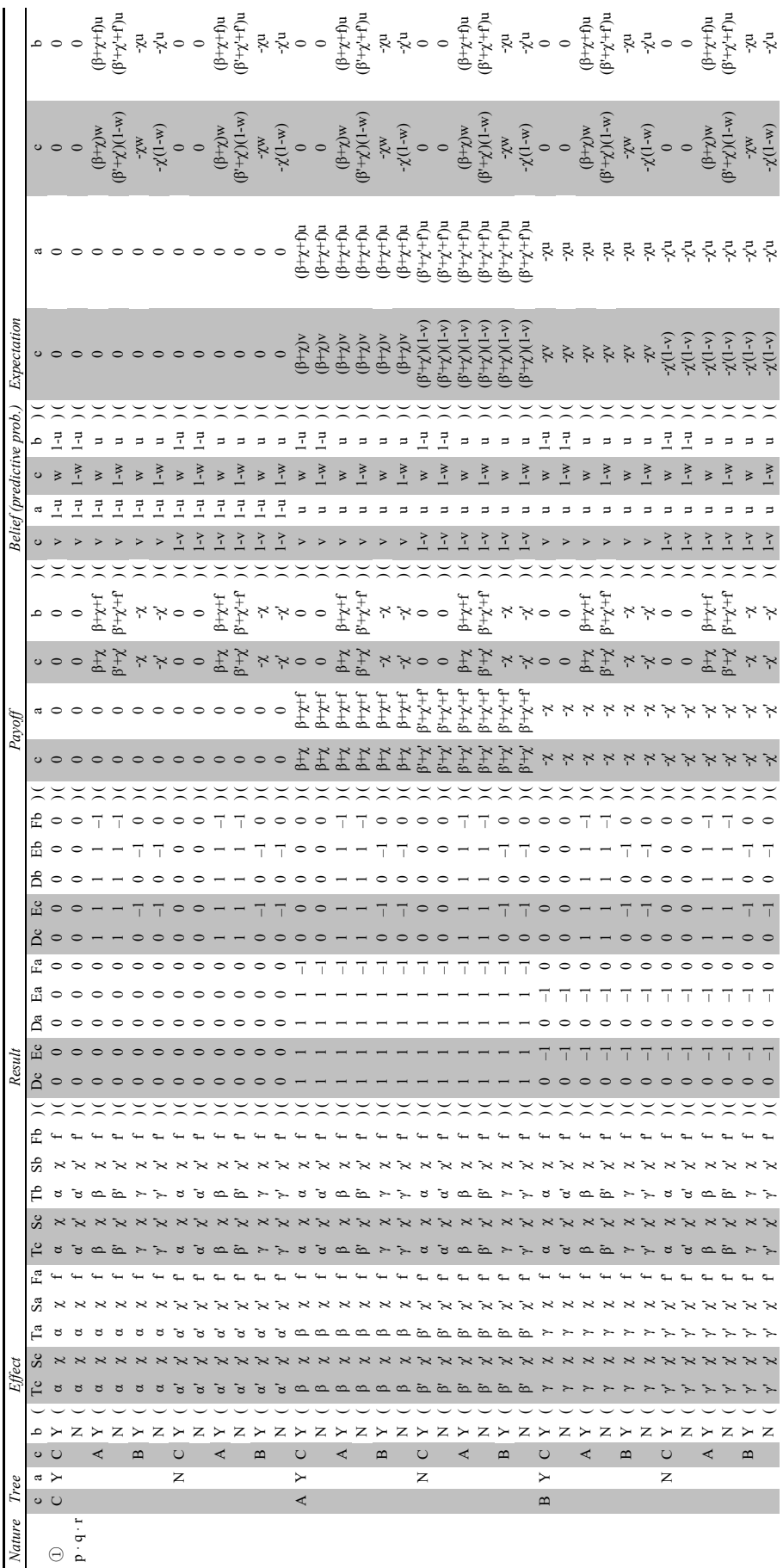


Table A2 The $\pm 1 / 0$ values of delay correction, separation correction and fuel consumption for each ACFT action in response to the ATC instructions

\begin{tabular}{|c|c|c|c|c|c|c|c|}
\hline \multirow[b]{2}{*}{ Instruction } & \multicolumn{3}{|c|}{ Time $T$} & \multicolumn{3}{|c|}{ Separation $S$} & \multirow{2}{*}{$\begin{array}{c}\text { Fuel F } \\
\begin{array}{c}\text { Consumption } \\
(f)\end{array}\end{array}$} \\
\hline & $\begin{array}{l}\text { On time } \\
\qquad(\alpha)\end{array}$ & $\begin{array}{c}\text { Delay } \\
(\beta)\end{array}$ & $\begin{array}{c}\text { Early } \\
(\gamma)\end{array}$ & $\begin{array}{c}\text { Even } \\
(\varphi)\end{array}$ & $\begin{array}{c}\text { Over } \\
(\chi)\end{array}$ & $\begin{array}{c}\text { Lack } \\
(\psi)\end{array}$ & \\
\hline Axel A & $\begin{array}{c}D_{i}(0) \\
=0\end{array}$ & $\begin{array}{c}D_{i}(1) \\
=1\end{array}$ & $\begin{array}{c}D_{i}(0) \\
=0\end{array}$ & $\begin{array}{c}E_{i}(-1) \\
=-1\end{array}$ & $\begin{array}{c}E_{i}(1) \\
=1\end{array}$ & $\begin{array}{c}E_{i}(-1) \\
=-1\end{array}$ & $F_{i}(-1)=-1$ \\
\hline Brake B & $\begin{array}{c}D_{i}(-1) \\
=-1\end{array}$ & $\begin{array}{c}D_{i}(-1) \\
=-1\end{array}$ & $\begin{array}{c}D_{i}(0) \\
=0\end{array}$ & $\begin{array}{c}E_{i}(-1) \\
=-1\end{array}$ & $\begin{array}{c}E_{i}(-1) \\
=-1\end{array}$ & $\begin{array}{c}E_{i}(1) \\
=1\end{array}$ & $F_{i}(0)=0$ \\
\hline Cont. C & $\begin{array}{c}D_{i}(0) \\
=0\end{array}$ & $\begin{array}{c}D_{i}(0) \\
=0\end{array}$ & $\begin{array}{c}D_{i}(0) \\
=0\end{array}$ & $\begin{array}{c}E_{i}(0) \\
=0\end{array}$ & $\begin{array}{c}E_{i}(0) \\
=0\end{array}$ & $\begin{array}{c}E_{i}(0) \\
=0\end{array}$ & $F_{i}(0)=0$ \\
\hline
\end{tabular}

The $\pm 1 / 0$ values of delay correction, separation correction and fuel consumption for each ACFT action in response to the ATC instructions can be summarised as follows:

- $\quad$ The value of delay correction is 0 if time $T$ is accelerated on-time; it is negative if $T$ is decelerated and it is 0 if $T$ is held constant. Moreover, its value is positive if $T$ is accelerated to delay, negative if $T$ is slowed down and 0 if $T$ is held constant.

Likewise, its value is 0 if $T$ is accelerated early, 0 if $T$ is slowed down and 0 if $T$ is held constant.

- The value of separation correction is negative if separation $S$ is properly accelerated, negative if $S$ is decelerated and 0 if $S$ is held constant. Moreover, its value is positive if $S$ is redundantly accelerated, negative if $S$ is decelerated and 0 if $S$ is held constant. Likewise, its value is 0 if $S$ is accelerated because of lack, positive if $S$ is decelerated and 0 if $S$ is held constant.

- $\quad$ The value of fuel consumption is negative if fuel $F$ is accelerated, 0 if $F$ is slowed down and 0 if $F$ is held constant.

Table A3 The $\pm 1 / 0$ values of delay correction, separation correction and fuel consumption for each ACFT action in response to the ATC instructions based on ACFT status (time and separation) by case

\begin{tabular}{|c|c|c|c|c|c|c|c|c|}
\hline \multirow[b]{2}{*}{$\begin{array}{l}\text { Case } \\
\text { (separation) }\end{array}$} & \multicolumn{4}{|c|}{$A C F T a_{i}$} & \multicolumn{4}{|c|}{$A C F T b_{i}$} \\
\hline & $\begin{array}{c}\text { Time } \\
T\end{array}$ & $\begin{array}{c}\text { Separation } \\
S\end{array}$ & Action & $\begin{array}{c} \pm(0) \text { of } \\
\text { exchangeable } \\
\text { value }\end{array}$ & $\begin{array}{c}\text { Time } \\
T\end{array}$ & $\begin{array}{c}\text { Separation } \\
S\end{array}$ & Action & $\begin{array}{c} \pm(0) \text { of } \\
\text { exchangeable } \\
\text { value }\end{array}$ \\
\hline \multirow[t]{3}{*}{$p_{i} q_{i} r_{i}$} & $\begin{array}{l}\text { On } \\
\text { time } \\
(\alpha)\end{array}$ & Over $(\chi)$ & $\begin{array}{c}\mathrm{C} / \mathrm{A} \\
\text { (C or } \\
\mathrm{A})\end{array}$ & $\begin{array}{c}D_{i}(0), E_{i}(0), \\
\quad F_{i}(0)\end{array}$ & $\begin{array}{c}\text { On } \\
\text { time } \\
(\alpha)\end{array}$ & Over $(\chi)$ & $\mathrm{C} / \mathrm{A}$ & $\begin{array}{c}D_{i}(0), E_{i}(0), \\
F_{i}(0)\end{array}$ \\
\hline & $\begin{array}{l}\text { Delay } \\
(\beta)\end{array}$ & $\operatorname{Over}(\chi)$ & A & $\begin{array}{l}D_{i}(1), E_{i}(1), \\
\quad F_{i}(-1)\end{array}$ & $\begin{array}{l}\text { Delay } \\
(\beta)\end{array}$ & $\operatorname{Over}(\chi)$ & A & $\begin{array}{c}D_{i}(1), E_{i}(1) \\
F_{i}(-1)\end{array}$ \\
\hline & $\begin{array}{l}\text { Early } \\
(\gamma)\end{array}$ & $\operatorname{Over}(\chi)$ & $\mathrm{B} / \mathrm{A}$ & $\begin{array}{c}D_{i}(0), E_{i}(-1), \\
F_{i}(0)\end{array}$ & $\begin{array}{c}\text { Early } \\
(\gamma)\end{array}$ & Over $(\chi)$ & $\mathrm{B} / \mathrm{A}$ & $\begin{array}{c}D_{i}(0), E_{i}(-1), \\
F_{i}(0)\end{array}$ \\
\hline \multirow[t]{2}{*}{$p_{i} q_{i}\left(1-r_{i}\right)$} & $\begin{array}{l}\text { On } \\
\text { time } \\
(\alpha)\end{array}$ & $\operatorname{Over}(\chi)$ & $\mathrm{C} / \mathrm{A}$ & $\begin{array}{c}D_{i}(0), E_{i}(0), \\
F_{i}(0)\end{array}$ & $\begin{array}{c}\text { On } \\
\text { time } \\
(\alpha)\end{array}$ & $\operatorname{Over}(\chi)$ & $\mathrm{C} / \mathrm{A}$ & $\begin{array}{c}D_{i}(0), E_{i}(1) \\
\quad F_{i}(-1)\end{array}$ \\
\hline & $\begin{array}{l}\text { Delay } \\
(\beta)\end{array}$ & $\operatorname{Over}(\chi)$ & A & $\begin{array}{c}D_{i}(1), E_{i}(1), \\
\quad F_{i}(-1)\end{array}$ & $\begin{array}{l}\text { Delay } \\
(\beta)\end{array}$ & $\operatorname{Over}(\chi)$ & A & $\begin{array}{c}D_{i}(1), E_{i}(1) \\
F_{i}(-1)\end{array}$ \\
\hline
\end{tabular}


Table A3 The $\pm 1 / 0$ values of delay correction, separation correction and fuel consumption for each ACFT action in response to the ATC instructions based on ACFT status (time and separation) by case (continued)

\begin{tabular}{|c|c|c|c|c|c|c|c|c|}
\hline \multirow[b]{2}{*}{$\begin{array}{l}\text { Case } \\
\text { (separation) }\end{array}$} & \multicolumn{4}{|c|}{$A C F T a_{i}$} & \multicolumn{4}{|c|}{$A C F T b_{i}$} \\
\hline & $\begin{array}{c}\text { Time } \\
T\end{array}$ & $\begin{array}{c}\text { Separation } \\
S\end{array}$ & Action & $\begin{array}{c} \pm(0) \text { of } \\
\text { exchangeable } \\
\text { value }\end{array}$ & $\begin{array}{c}\text { Time } \\
T\end{array}$ & $\begin{array}{c}\text { Separation } \\
S\end{array}$ & Action & $\begin{array}{c} \pm(0) \text { of } \\
\text { exchangeable } \\
\text { value }\end{array}$ \\
\hline$p_{i} q_{i}\left(1-r_{i}\right)$ & $\begin{array}{l}\text { Early } \\
(\gamma)\end{array}$ & $\operatorname{Over}(\chi)$ & $\mathrm{B} / \mathrm{A}$ & $\begin{array}{c}D_{i}(0), E_{i}(-1), \\
F_{i}(0)\end{array}$ & $\begin{array}{l}\text { Early } \\
(\gamma)\end{array}$ & $\operatorname{Over}(\chi)$ & $\mathrm{B} / \mathrm{A}$ & $\begin{array}{l}D_{i}(0), E_{i}(1), \\
\quad F_{i}(-1)\end{array}$ \\
\hline \multirow[t]{3}{*}{$p_{i}\left(1-q_{i}\right) r_{i}$} & $\begin{array}{l}\text { On } \\
\text { time } \\
(\alpha)\end{array}$ & Over $(\chi)$ & $\mathrm{C} / \mathrm{A}$ & $\begin{array}{c}D_{i}(0), E_{i}(1) \\
\quad F_{i}(-1)\end{array}$ & $\begin{array}{l}\text { On } \\
\text { time } \\
(\alpha)\end{array}$ & Lack $(\psi)$ & $\mathrm{C} / \mathrm{B}$ & $\begin{array}{c}D_{i}(-1), E_{i}(1), \\
F_{i}(0)\end{array}$ \\
\hline & $\begin{array}{l}\text { Delay } \\
(\beta)\end{array}$ & Over $(\chi)$ & A & $\begin{array}{c}D_{i}(1), E_{i}(1) \\
\quad F_{i}(-1)\end{array}$ & $\begin{array}{l}\text { Delay } \\
(\beta)\end{array}$ & Lack $(\psi)$ & $\mathrm{A} / \mathrm{B}$ & $\begin{array}{c}D_{i}(-1), E_{i}(1), \\
F_{i}(0)\end{array}$ \\
\hline & $\begin{array}{l}\text { Early } \\
(\gamma)\end{array}$ & Over $(\chi)$ & $\mathrm{B} / \mathrm{A}$ & $\begin{array}{c}D_{i}(0), E_{i}(1) \\
\quad F_{i}(-1)\end{array}$ & $\begin{array}{l}\text { Early } \\
(\gamma)\end{array}$ & Lack $(\psi)$ & B & $\begin{array}{l}D_{i}(0), E_{i}(1), \\
\quad F_{i}(0)\end{array}$ \\
\hline \multirow[t]{3}{*}{$\begin{array}{l}p_{i}\left(1-q_{i}\right) \\
\left(1-r_{i}\right)\end{array}$} & $\begin{array}{l}\text { On } \\
\text { time } \\
(\alpha)\end{array}$ & Over $(\chi)$ & $\mathrm{C} / \mathrm{A}$ & $\begin{array}{c}D_{i}(0), E_{i}(1) \\
\quad F_{i}(-1)\end{array}$ & $\begin{array}{l}\text { On } \\
\text { time } \\
(\alpha)\end{array}$ & Lack $(\psi)$ & $\begin{array}{l}\mathrm{C} / \mathrm{B} \\
\Rightarrow \mathrm{B}\end{array}$ & $\begin{array}{c}D_{i}(-1), E_{i}(1) \\
F_{i}(0)\end{array}$ \\
\hline & $\begin{array}{l}\text { Delay } \\
(\beta)\end{array}$ & $\operatorname{Over}(\chi)$ & A & $\begin{array}{c}D_{i}(1), E_{i}(1) \\
\quad F_{i}(-1)\end{array}$ & $\begin{array}{l}\text { Delay } \\
(\beta)\end{array}$ & Lack $(\psi)$ & $\begin{array}{l}\mathrm{A} / \mathrm{B} \\
\Rightarrow \mathrm{B}\end{array}$ & $\begin{array}{c}D_{i}(-1), E_{i}(1), \\
F_{i}(0)\end{array}$ \\
\hline & $\begin{array}{c}\text { Early } \\
(\gamma)\end{array}$ & $\operatorname{Over}(\chi)$ & $\mathrm{B} / \mathrm{A}$ & $\begin{array}{c}D_{i}(0), E_{i}(1) \\
\quad F_{i}(-1)\end{array}$ & $\begin{array}{c}\text { Early } \\
(\gamma)\end{array}$ & Lack $(\psi)$ & B & $\begin{array}{l}D_{i}(0), E_{i}(1), \\
\quad F_{i}(0)\end{array}$ \\
\hline \multirow[t]{3}{*}{$\left(1-p_{i}\right) q_{i} r_{i}$} & $\begin{array}{l}\text { On } \\
\text { time } \\
(\alpha)\end{array}$ & Lack $(\psi)$ & $\mathrm{C} / \mathrm{B}$ & $\begin{array}{c}D_{i}(-1), E_{i}(1), \\
F_{i}(0)\end{array}$ & $\begin{array}{l}\text { On } \\
\text { time } \\
(\alpha)\end{array}$ & $\operatorname{Over}(\chi)$ & $\mathrm{C} / \mathrm{A}$ & $\begin{array}{l}D_{i}(0), E_{i}(0), \\
\quad F_{i}(0)\end{array}$ \\
\hline & $\begin{array}{l}\text { Delay } \\
(\beta)\end{array}$ & Lack $(\psi)$ & $\mathrm{A} / \mathrm{B}$ & $\begin{array}{c}D_{i}(-1), E_{i}(1) \\
F_{i}(0)\end{array}$ & $\begin{array}{l}\text { Delay } \\
(\beta)\end{array}$ & Over $(\chi)$ & A & $\begin{array}{l}D_{i}(1), E_{i}(1), \\
\quad F_{i}(-1)\end{array}$ \\
\hline & $\begin{array}{l}\text { Early } \\
(\gamma)\end{array}$ & Lack $(\psi)$ & B & $\begin{array}{c}D_{i}(0), E_{i}(1) \\
F_{i}(0)\end{array}$ & $\begin{array}{c}\text { Early } \\
(\gamma)\end{array}$ & Over $(\chi)$ & $\mathrm{B} / \mathrm{A}$ & $\begin{array}{c}D_{i}(0), E_{i}(-1), \\
F_{i}(0)\end{array}$ \\
\hline \multirow[t]{3}{*}{$\begin{array}{l}\left(1-p_{i}\right) \\
q_{i}\left(1-r_{i}\right)\end{array}$} & $\begin{array}{l}\text { On } \\
\text { time } \\
(\alpha)\end{array}$ & Lack $(\psi)$ & $\mathrm{C} / \mathrm{B}$ & $\begin{array}{c}D_{i}(-1), E_{i}(0) \\
F_{i}(0)\end{array}$ & $\begin{array}{c}\text { On } \\
\text { time } \\
(\alpha)\end{array}$ & Over $(\chi)$ & $\mathrm{C} / \mathrm{A}$ & $\begin{array}{l}D_{i}(0), E_{i}(1), \\
\quad F_{i}(-1)\end{array}$ \\
\hline & $\begin{array}{l}\text { Delay } \\
(\beta)\end{array}$ & $\operatorname{Lack}(\psi)$ & $\mathrm{A} / \mathrm{B}$ & $\begin{array}{c}D_{i}(-1), E_{i}(0) \\
F_{i}(0)\end{array}$ & $\begin{array}{l}\text { Delay } \\
(\beta)\end{array}$ & $\operatorname{Over}(\chi)$ & A & $\begin{array}{l}D_{i}(1), E_{i}(1), \\
\quad F_{i}(-1)\end{array}$ \\
\hline & $\begin{array}{c}\text { Early } \\
(\gamma)\end{array}$ & Lack $(\psi)$ & B & $\begin{array}{c}D_{i}(0), E_{i}(0) \\
F_{i}(0)\end{array}$ & $\begin{array}{c}\text { Early } \\
(\gamma)\end{array}$ & $\operatorname{Over}(\chi)$ & $\mathrm{B} / \mathrm{A}$ & $\begin{array}{l}D_{i}(0), E_{i}(1), \\
\quad F_{i}(-1)\end{array}$ \\
\hline \multirow[t]{3}{*}{$\begin{array}{l}\left(1-p_{i}\right) \\
\left(1-q_{i}\right) r_{i}\end{array}$} & $\begin{array}{c}\text { On } \\
\text { time } \\
(\alpha)\end{array}$ & Lack $(\psi)$ & $\begin{array}{l}\mathrm{C} / \mathrm{B} \\
\Rightarrow \mathrm{B}\end{array}$ & $\begin{array}{c}D_{i}(-1), E_{i}(1) \\
F_{i}(0)\end{array}$ & $\begin{array}{c}\text { On } \\
\text { time } \\
(\alpha)\end{array}$ & Lack $(\psi)$ & $\mathrm{C} / \mathrm{B}$ & $\begin{array}{c}D_{i}(-1), E_{i}(1) \\
F_{i}(0)\end{array}$ \\
\hline & $\begin{array}{l}\text { Delay } \\
(\beta)\end{array}$ & Lack $(\psi)$ & $\begin{array}{l}\mathrm{A} / \mathrm{B} \\
\Rightarrow \mathrm{B}\end{array}$ & $\begin{array}{c}D_{i}(-1), E_{i}(1) \\
F_{i}(0)\end{array}$ & $\begin{array}{l}\text { Delay } \\
(\beta)\end{array}$ & Lack $(\psi)$ & $\mathrm{A} / \mathrm{B}$ & $\begin{array}{c}D_{i}(-1), E_{i}(1) \\
F_{i}(0)\end{array}$ \\
\hline & $\begin{array}{l}\text { Early } \\
(\gamma)\end{array}$ & Lack $(\psi)$ & B & $\begin{array}{c}D_{i}(0), E_{i}(1), \\
F_{i}(0)\end{array}$ & $\begin{array}{l}\text { Early } \\
(\gamma)\end{array}$ & Lack $(\psi)$ & B & $\begin{array}{c}D_{i}(0), E_{i}(1), \\
\quad F_{i}(0)\end{array}$ \\
\hline $\begin{array}{l}\left(1-p_{i}\right) \\
\left(1-q_{i}\right) \\
\left(1-r_{i}\right)\end{array}$ & $\begin{array}{c}\text { On } \\
\text { time } \\
(\alpha)\end{array}$ & Lack $(\psi)$ & $\begin{array}{l}\mathrm{C} / \mathrm{B} \\
\Rightarrow \mathrm{B}\end{array}$ & $\begin{array}{c}D_{i}(-1), E_{i}(1) \\
F_{i}(0)\end{array}$ & $\begin{array}{c}\text { On } \\
\text { time } \\
(\alpha)\end{array}$ & Lack $(\psi)$ & $\begin{array}{l}\mathrm{C} / \mathrm{B} \\
\Rightarrow \mathrm{B}\end{array}$ & $\begin{array}{c}D_{i}(-1), E_{i}(1), \\
F_{i}(0)\end{array}$ \\
\hline
\end{tabular}


Table A3 The $\pm 1 / 0$ values of delay correction, separation correction and fuel consumption for each ACFT action in response to the ATC instructions based on ACFT status (time and separation) by case (continued)

\begin{tabular}{|c|c|c|c|c|c|c|c|c|}
\hline \multirow[b]{2}{*}{$\begin{array}{l}\text { Case } \\
\text { (separation) }\end{array}$} & \multicolumn{4}{|c|}{$A C F T a_{i}$} & \multicolumn{4}{|c|}{$A C F T b_{i}$} \\
\hline & $\begin{array}{c}\text { Time } \\
T\end{array}$ & $\begin{array}{c}\text { Separation } \\
S\end{array}$ & Action & $\begin{array}{c} \pm(0) \text { of } \\
\text { exchangeable } \\
\text { value }\end{array}$ & $\begin{array}{c}\text { Time } \\
T\end{array}$ & $\begin{array}{c}\text { Separation } \\
S\end{array}$ & Action & $\begin{array}{c} \pm(0) \text { of } \\
\text { exchangeable } \\
\text { value }\end{array}$ \\
\hline \multirow{2}{*}{$\begin{array}{l}\left(1-p_{i}\right) \\
\left(1-q_{i}\right) \\
\left(1-r_{i}\right)\end{array}$} & $\begin{array}{l}\text { Delay } \\
(\beta)\end{array}$ & Lack $(\psi)$ & $\begin{array}{l}\mathrm{A} / \mathrm{B} \\
\Rightarrow \mathrm{B}\end{array}$ & $\begin{array}{c}D_{i}(-1), E_{i}(1) \\
F_{i}(0)\end{array}$ & $\begin{array}{l}\text { Delay } \\
(\beta)\end{array}$ & Lack $(\psi)$ & $\begin{array}{l}\mathrm{A} / \mathrm{B} \\
\Rightarrow \mathrm{B}\end{array}$ & $\begin{array}{c}D_{i}(-1), E_{i}(1), \\
F_{i}(0)\end{array}$ \\
\hline & $\begin{array}{c}\text { Early } \\
(\gamma)\end{array}$ & Lack $(\psi)$ & B & $\begin{array}{c}D_{i}(0), E_{i}(1), \\
\quad F_{i}(0)\end{array}$ & $\begin{array}{l}\text { Early } \\
(\gamma)\end{array}$ & Lack $(\psi)$ & B & $\begin{array}{c}D_{i}(0), E_{i}(1), \\
\quad F_{i}(0)\end{array}$ \\
\hline
\end{tabular}

The $\pm 1 / 0$ values of delay correction, separation correction and fuel consumption for each ACFT action in response to the ATC instructions based on ACFT status (time and separation) by case are summarised in Table A4.

Table A4 Path with the maximum gain, expected gain and case gain

\begin{tabular}{|c|c|c|c|c|}
\hline $\begin{array}{l}\text { Case } \\
j\end{array}$ & $\begin{array}{l}\text { Separation } \\
\text { probability } \\
f\left(p_{i}, q_{i}, r_{i}\right)_{j} \\
\end{array}$ & $\begin{array}{l}\text { Path with the } \\
\text { maximum gain }\end{array}$ & (1) Expected gain $i$ & (2) Case gain $E c_{j}$, $a_{j i}, b_{j i}$ \\
\hline \multirow[t]{3}{*}{$\begin{array}{l}\text { Case } \\
\text { (1) }\end{array}$} & $p_{i} q_{i} r_{i}$ & AY-AY, AY-AN & $\begin{array}{c}(\beta+\chi)\left(v_{i}+w_{i}\right) \\
(\beta+\chi) v_{i}+\left(\beta+\chi^{\prime}\right) \\
\left(1-w_{i}\right)\end{array}$ & $\begin{array}{c}E c 1=(\beta-\beta)\left(v_{i}+w_{i}\right) \\
+2 \beta\end{array}$ \\
\hline & & AN-AN, AN-AY & $\begin{aligned} & \left(\beta+\chi^{\prime}\right)\left\{\left(1-v_{i}\right)\right. \\
+ & \left.\left(1-w_{i}\right)\right\},\left(\beta+\chi^{\prime}\right) \\
& \left(1-v_{i}\right)+(\beta+\chi)\end{aligned}$ & $E a 1_{i}=\left[\left(\beta+\beta^{\prime}\right)+\left(f+f^{\prime}\right)\right] u_{i}$ \\
\hline & & & & $E b 1_{i}=\left[(\beta+\beta)+\left(f+f^{\prime}\right)\right] u_{i}$ \\
\hline \multirow[t]{3}{*}{$\begin{array}{l}\text { Case } \\
\text { (2) }\end{array}$} & $p_{i} q_{i}\left(1-r_{i}\right)$ & AN-AN, AN-AY & $\begin{array}{c}(\beta+\chi)\left(v_{i}+w_{i}\right) \\
(\beta+\chi) v_{i}+\left(\beta+\chi^{\prime}\right) \\
\left(1-w_{i}\right)\end{array}$ & $\begin{array}{c}E c 2=(\beta-\beta) v_{i}+\left\{3\left(\chi-\chi^{\prime}\right)\right. \\
+(\beta-\beta)\} w_{i}+\left(3 \chi^{\prime}+2 \beta^{\prime}\right)\end{array}$ \\
\hline & & AN-AN, AN-AY & $\begin{aligned} & \left(\beta+\chi^{\prime}\right)\left\{\left(1-v_{i}\right)\right. \\
+ & \left.\left(1-w_{i}\right)\right\},\left(\beta+\chi^{\prime}\right) \\
& \left(1-v_{i}\right)+(\beta+\chi) w_{i}\end{aligned}$ & $E a 2_{i}=\left[(\beta+\beta)+\left(f+f^{\prime}\right)\right] u_{i}$ \\
\hline & & & & $\begin{aligned} E b 2_{i}= & {\left[3\left(\chi+\chi^{\prime}\right)+\{(\beta+\beta)\right.} \\
& \left.\left.-3\left(f+f^{\prime}\right)\right\}\right] u_{i}\end{aligned}$ \\
\hline \multirow[t]{3}{*}{$\begin{array}{l}\text { Case } \\
\text { (3) }\end{array}$} & $p_{i}\left(1-q_{i}\right) r_{i}$ & AY-BY, AY-BN & $\begin{array}{c}\chi v_{i}+\psi w_{i}, \chi v_{i}+\psi^{\prime} \\
\left(1-w_{i}\right)\end{array}$ & $\begin{array}{c}E c 3=\left\{3\left(\chi-\chi^{\prime}\right)+(\beta\right. \\
-\beta)\} v_{i}+\left[3\left(\psi-\psi^{\prime}\right)+\{-(\alpha\right. \\
-\alpha)-(\beta-\beta)\}] w_{i}+\left\{3\left(\chi^{\prime}\right.\right. \\
\left.\left.+\psi^{\prime}\right)-\alpha\right\}\end{array}$ \\
\hline & & AN-BN, AN-BY & $\begin{array}{c}\chi^{\prime}\left(1-v_{i}\right)+\psi^{\prime}\left(1-w_{i}\right), \\
\chi^{\prime}\left(1-v_{i}\right)+\psi^{\prime} w_{i}\end{array}$ & $\begin{aligned} E a 3_{i}= & {\left[3\left(\chi+\chi^{\prime}\right)+\{(\beta+\beta)\right.} \\
& \left.\left.-3\left(f+f^{\prime}\right)\right\}\right] u_{i}\end{aligned}$ \\
\hline & & & & $\begin{array}{c}E b 3_{i}=\left[3\left(\psi+\psi^{\prime}\right)+\{-(\alpha\right. \\
\left.\left.\quad+\alpha)-\left(\beta+\beta^{\prime}\right)\right\}\right] u_{i}\end{array}$ \\
\hline $\begin{array}{l}\text { Case } \\
\text { (4) }\end{array}$ & $\begin{array}{l}p_{i}\left(1-q_{i}\right) \\
\quad\left(1-r_{i}\right)\end{array}$ & AY-BY, AY-BN & $\begin{array}{c}\chi v_{i}+\psi w_{i}, \chi v_{i}+\psi^{\prime} \\
\left(1-w_{i}\right)\end{array}$ & $\begin{array}{c}E c 4=\left\{3\left(\chi-^{\prime}\right)+(\beta-\beta)\right\} v_{i} \\
+\left[3\left(\psi-\psi^{\prime}\right)+\{-(\alpha-\alpha)\right. \\
-(\beta-\beta)\}] w_{i}+\left\{3\left(\chi^{\prime}+\psi^{\prime}\right)\right. \\
-\alpha\}\end{array}$ \\
\hline
\end{tabular}


Table A4 Path with the maximum gain, expected gain and case gain (continued)

\begin{tabular}{|c|c|c|c|c|}
\hline $\begin{array}{l}\text { Case } \\
j\end{array}$ & $\begin{array}{l}\text { Separation } \\
\text { probability } \\
f\left(p_{i}, q_{i}, r_{i}\right)_{j}\end{array}$ & $\begin{array}{l}\text { Path with the } \\
\text { maximum gain }\end{array}$ & (1) Expected gain $i$ & (2) Case gain $E_{c_{j}}, a_{j i}, b_{j i}$ \\
\hline \multirow[t]{2}{*}{$\begin{array}{l}\text { Case } \\
\text { (4) }\end{array}$} & $\begin{array}{l}p_{i}\left(1-q_{i}\right) \\
\quad\left(1-r_{i}\right)\end{array}$ & AN-BN, AN-BY & $\begin{array}{c}\chi^{\prime}\left(1-v_{i}\right)+\psi^{\prime}\left(1-w_{i}\right) \\
\chi^{\prime}\left(1-v_{i}\right)+\psi^{\prime} w_{i}\end{array}$ & $\begin{aligned} E a 4_{i}= & {\left[3\left(\chi+\chi^{\prime}\right)+\{(\beta+\beta)\right.} \\
& \left.\left.-3\left(f+f^{\prime}\right)\right\}\right] u_{i}\end{aligned}$ \\
\hline & & & & $\begin{array}{c}E b 4_{i}=\left[3\left(\psi+\psi^{\prime}\right)\right. \\
\left.+\left\{-\left(\alpha+\alpha^{\prime}\right)-(\beta+\beta)\right\}\right] u_{i}\end{array}$ \\
\hline \multirow[t]{3}{*}{$\begin{array}{l}\text { Case } \\
\text { (5) }\end{array}$} & $\left(1-p_{i}\right) q_{i} r_{i}$ & BY-AY, BY-AN & $\begin{array}{l}\psi v_{i}+(\beta+\chi) w_{i}, \psi v_{i} \\
+\left(\beta+\chi^{\prime}\right)\left(1-w_{i}\right)\end{array}$ & $\begin{array}{c}E c 5=\left[3\left(\psi-\psi^{\prime}\right)\right. \\
+\{-(\alpha-\alpha)-(\beta-\beta)\}] v_{i} \\
+(\beta-\beta) w_{i}+\left(3 \psi^{\prime}-\alpha\right)\end{array}$ \\
\hline & & BN-AN, BN-AY & $\begin{array}{c}\psi^{\prime}\left(1-v_{i}\right)+\left(\beta+\chi^{\prime}\right) \\
\left(1-w_{i}\right), \psi^{\prime}\left(1-v_{i}\right) \\
+(\beta+\chi) w_{i}\end{array}$ & $\begin{array}{l}E a 5_{i}=\left[3\left(\psi+\psi^{\prime}\right)+\{-(\alpha\right. \\
\left.\left.\left.\quad+\alpha^{\prime}\right)-\left(\beta+\beta^{\prime}\right)\right\}\right] u_{i}\end{array}$ \\
\hline & & & & $E b 5_{i}=\left[(\beta+\beta)+\left(f+f^{\prime}\right)\right] u_{i}$ \\
\hline \multirow[t]{3}{*}{$\begin{array}{l}\text { Case } \\
\text { (6) }\end{array}$} & $\begin{array}{c}\left(1-p_{i}\right) \\
q_{i}\left(1-r_{i}\right)\end{array}$ & BY-AY, BY-AN & $\begin{array}{c}\psi v_{i}+\chi w_{i}, \psi v_{i}+\chi^{\prime} \\
\left(1-w_{i}\right)\end{array}$ & $\begin{aligned} E c 6= & {\left[3\left(\psi-\psi^{\prime}\right)+\{-(\alpha\right.} \\
-\alpha)- & (\beta-\beta)\}] v_{i}+\{3(\chi \\
\left.-\chi^{\prime}\right)+ & (\beta-\beta)\} w_{i}+\left\{3\left(\chi^{\prime}\right.\right. \\
+ & \left.\left.\psi^{\prime}\right)-\alpha\right\}\end{aligned}$ \\
\hline & & BN-AN, BN-AY & $\begin{array}{c}\psi^{\prime}\left(1-v_{i}\right)+\chi^{\prime}\left(1-w_{i}\right) \\
\psi^{\prime}\left(1-v_{i}\right)+\chi w_{i}\end{array}$ & $\begin{array}{c}E a 6_{i}=\left[3\left(\psi+\psi^{\prime}\right)+\{-(\alpha\right. \\
+\alpha)-(\beta+\beta)\}] u_{i}\end{array}$ \\
\hline & & & & $\begin{aligned} E b 6_{i}= & {\left[3\left(\chi+\chi^{\prime}\right)+\{(\beta+\beta)\right.} \\
& \left.\left.-3\left(f+f^{\prime}\right)\right\}\right] u_{i}\end{aligned}$ \\
\hline \multirow[t]{3}{*}{$\begin{array}{l}\text { Case } \\
\text { (7) }\end{array}$} & $\begin{array}{l}\left(1-p_{i}\right) \\
\left(1-q_{i}\right) r_{i}\end{array}$ & $\mathrm{BY}-\mathrm{BY}, \mathrm{BY}-\mathrm{BN}$ & $\begin{array}{c}\psi v_{i}+\psi w_{i}, \psi v_{i}+\psi^{\prime} \\
\left(1-w_{i}\right)\end{array}$ & $\begin{array}{c}E c 7=\left[3\left(\psi-\psi^{\prime}\right)+\{-(\alpha\right. \\
-\alpha)-(\beta-\beta)\}]\left(v_{i}+w_{i}\right) \\
+2\left\{3 \psi^{\prime}+(-\alpha-\beta)\right\}\end{array}$ \\
\hline & & $\mathrm{BN}-\mathrm{BN}, \mathrm{BN}-\mathrm{BY}$ & $\begin{array}{c}\psi^{\prime}\left(1-v_{i}\right)+\chi^{\prime}\left(1-w_{i}\right) \\
\psi^{\prime}\left(1-v_{i}\right)+\psi w_{i}\end{array}$ & $\begin{array}{l}E a 7_{i}=\left[3\left(\psi+\psi^{\prime}\right)+\{-(\alpha\right. \\
\quad+\alpha)-(\beta+\beta)\}] u_{i}\end{array}$ \\
\hline & & & & $\begin{array}{l}E b 7_{i}=\left[3\left(\psi+\psi^{\prime}\right)+\{-(\alpha\right. \\
\left.\left.\left.\quad+\alpha^{\prime}\right)-(\beta+\beta)\right\}\right] u_{i}\end{array}$ \\
\hline \multirow[t]{3}{*}{$\begin{array}{l}\text { Case } \\
\text { (8) }\end{array}$} & $\begin{array}{l}\left(1-p_{i}\right) \\
\left(1-q_{i}\right) \\
\left(1-r_{i}\right)\end{array}$ & BY-BY, BY-BN & $\begin{array}{c}\psi v_{i}+\psi w w_{i}, \psi v_{i}+\psi^{\prime} \\
\left(1-w_{i}\right)\end{array}$ & $\begin{array}{c}E c 8=\left[3\left(\psi-\psi^{\prime}\right)+\{-(\alpha\right. \\
-\alpha)-(\beta-\beta)\}]\left(v_{i}+w_{i}\right) \\
+2\left\{3 \psi^{\prime}+(-\alpha-\beta)\right\}\end{array}$ \\
\hline & & $\mathrm{BN}-\mathrm{BN}, \mathrm{BN}-\mathrm{BY}$ & $\begin{array}{c}\psi^{\prime}\left(1-v_{i}\right)+\chi^{\prime}\left(1-w_{i}\right) \\
\psi^{\prime}\left(1-v_{i}\right)+\psi w_{i}\end{array}$ & $\begin{array}{l}E a 8_{i}=\left[3\left(\psi+\psi^{\prime}\right)+\{-(\alpha\right. \\
\quad+\alpha)-(\beta+\beta)\}] u_{i}\end{array}$ \\
\hline & & & & $\begin{array}{l}E b 8_{i}=\left[3\left(\psi+\psi^{\prime}\right)+\{-(\alpha\right. \\
\left.\left.\quad+\alpha)-\left(\beta+\beta^{\prime}\right)\right\}\right] u_{i}\end{array}$ \\
\hline
\end{tabular}

If the distance between the consequent ACFTs is given by $\left(p_{i}, q_{i}, r_{i}\right)$, then $S$ is over if $T$ is on-time; thus, the action of ACFT $a_{i}$ in response to the instruction of ATC $c$ is continued $\mathrm{C}$, the value of the delay correction is 0 , the value of the separation correction is 0 and the value of fuel consumption is 0 . Moreover, the action of ACFT $b_{i}-$ as instructed by ATC $c-$ is continued $\mathrm{C}$, the value of the delay correction is 0 , the exchangeable value of the separation correction is 0 and the exchangeable value of fuel consumption is 0 . For the cases $p_{i}\left(1-q_{i}\right)\left(1-r_{i}\right),\left(1-p_{i}\right)\left(1-q_{i}\right) r_{i},\left(1-p_{i}\right)\left(1-q_{i}\right)\left(1-r_{i}\right)$, fuel consumption is the 
safety first and the ATC and ACFT choose to secure the end-to-top separation such that backward delay propagation is not stopped.

Table A5 Total case gain (gain function)

\begin{tabular}{ll}
\hline Player & Total case gain (gain function) \\
\hline ATC $c$ & $E c=f c\left(u_{i}, v_{i}, w_{i}\right)=\sum_{j} f\left(p_{i}, q_{i}, r_{i}\right)_{j} E c_{j}=\left[3\left\{p_{i}\left(1-q_{i}\right)\left(\chi-\chi^{\prime}\right)+\left(1-p_{i}\right)\left(\psi-\psi^{\prime}\right)\right\}\right.$ \\
& \\
& $\left.+\left\{-\left(1-p_{i}\right)(\alpha-\alpha)+\left(2 p_{i}-1\right)(\beta-\beta)\right\}\right] v_{i}+\left[3\left\{q_{i}\left(1-r_{i}\right)\left(\chi-\chi^{\prime}\right)+\left(1-q_{i}\right)\right.\right.$ \\
& $\left.\left.\left(\psi-\psi^{\prime}\right)\right\}+\left\{-\left(1-q_{i}\right)(\alpha-\alpha)+\left(2 q_{i}-1\right)(\beta-\beta)\right\}\right] w_{i}+3\left[\left\{p_{i}\left(1-q_{i}\right)+q_{i}\left(1-r_{i}\right)\right\} \chi^{\prime}\right.$ \\
& $\left.+\left\{\left(1-p_{i}\right)+\left(1-q_{i}\right)\right\} \psi^{\prime}\right]+\left[-\left\{\left(1-p_{i}\right)+\left(1-q_{i}\right)\right\} \alpha+\left\{\left(2 p_{i}-1\right)+\left(2 q_{i}-1\right)\right\} \beta^{\prime}\right]$ \\
& $\equiv C c_{1} \cdot v_{i}+C c_{2} \cdot w_{i}+C o$
\end{tabular}

